\title{
US economic uncertainty and the Korean stock market reaction
}




\begin{abstract}
This paper examines whether US economic uncertainty is significantly priced in the Korean stock markets. Our results show that stocks highly sensitive to US economic uncertainty with positively or negatively large uncertainty betas have lower future returns. Motivated by Miller's (1977) and Hong and Sraer's (2016) overpricing explanation, we suggest that these stocks are more likely to be exposed to greater divergence of opinions and thus overpriced. More importantly, we further suggest that the large proportion of retail investors which is a distinctive feature of the Korean stock markets contributes to overpricing by limiting arbitrage. Utilizing our unique intraday data, we measure limits to arbitrage with levels of retail trading, and find further supporting evidence that overpricing is significant only within stocks with high limits to arbitrage and in during high retail-sentiment period.
\end{abstract}

Classification codes: G10; G12; G40

Keywords: Uncertainty; Economic uncertainty; Emerging stock market; Korean stock market; Limits to arbitrage; Sentiment 


\section{Introduction}

In this paper, we examine whether US economic uncertainty is significantly priced in the Korean stock markets from January 1992 to June 2017. Based on the previous studies, we set two hypotheses on how economic uncertainty is priced and investigate the impact of economic uncertainty in the Korean stock markets. To start with, we mainly follow Bali et al.'s (2017) methodology to investigate the pricing effect of economic uncertainty. Using the economic uncertainty measure suggested by Jurado et al. (2015), Bali et al. (2017) estimate each stock's sensitivity to uncertainty and call this sensitivity the uncertainty beta. Stocks with a high uncertainty beta have high returns in a state of high uncertainty, which is favorable to investors in managing their risk. Specifically, if investors obtain high returns in an unfavorable state of high uncertainty and can thus hedge their uncertainty risk, then these stocks will have low expected returns. Consequently, since Bali et al. (2017) find empirical evidence of this in US markets, we could expect a negative premium on the uncertainty beta. In this paper, we call this hypothesis the negative premium hypothesis.

On the other hand, motivated by the literature on the market beta in the capital asset pricing model, we propose another hypothesis on the relation between the economic uncertainty beta and the expected stock return. According to the CAPM, stocks with a high market beta should have higher future returns, but according to the empirical studies on the stock market beta (Baker et al., 2011; Frazzini and Pedersen, 2014), stocks with a high market beta tend to have lower future returns than those with a low market beta. Hong and Sraer (2016) explain this phenomenon based on Miller's (1977) hypothesis and suggest that highmarket beta stocks are more likely to be overpriced due to short-sales constraints. Motivated by Hong and Sraer's (2016) model which assumes that high-market beta stocks are exposed to a greater divergence of opinion, we assume stocks that are highly— positively or negatively—sensitive to economic uncertainty to 
be exposed to a greater divergence of opinions and thus be overpriced. ${ }^{1}$ This overpricing will generate an inverted U-shaped relation between expected returns and the uncertainty beta, since both positively and negatively large uncertainty beta stocks will generate lower future returns. Moreover, according to Stambaugh et al. (2012) and Miller (1977), we can expect this overpricing to be more prominent when there is high limits to arbitrage and in high-sentiment periods than in low-sentiment periods. We call this hypothesis the overpricing hypothesis.

Based on these two competing hypotheses - the negative premium hypothesis and the overpricing hypothesis - we first examine the relation between expected returns and the uncertainty beta by forming univariate-sorted portfolios. According to the negative premium hypothesis, future returns on a portfolio would monotonically decrease as the uncertainty beta increases. By contrast, the overpricing hypothesis suggests an inverted U-shaped pattern of future returns across uncertainty betas and, thus, a monotonic pattern will be observed if we sort stocks by the absolute value of the uncertainty beta (absolute uncertainty beta). Our empirical results strongly support the overpricing hypothesis and reject the negative premium hypothesis. Expected returns across absolute uncertainty beta-sorted portfolios appear to monotonically increase as the absolute uncertainty beta increases but show no pattern if we sort stocks by the uncertainty beta. Cross-sectional analysis also shows consistent results, supporting the overpricing hypothesis.

To further investigate the overpricing hypothesis, we investigate the effect of large retail investors in the Korean stock market using the unique transaction and quote data. From the perspective of the overpricing hypothesis, the negative relation between expected returns and the absolute uncertainty beta should be dominant within firms with high limits to arbitrage. The literature has documented that retail

\footnotetext{
${ }^{1}$ The disagreement measures are used as proxies for uncertainty in many previous empirical studies (Sill, 2012; Bloom, 2009; Wright, 2011; Makarova, 2014) though 'disagreement' and 'uncertainty' may have some differences. Hong and Sraer (2016) also use an index of the dispersion of macroforecasts from the Survey of Professional Forecasters as a proxy for aggregate disagreement, which is interpreted as economic uncertainty by Sill (2012) and Bloom (2009). Moreover, according to the classification of Walker et al. (2003), aggregate disagreement can be classified as epistemic uncertainty, which is generated by imperfect knowledge of the system by the experts.
} 
trading can limit arbitrage. ${ }^{2}$ Thus, to investigate the effects of retail investors on the relation between the uncertainty beta and expected returns, we use Korean stock market transaction and quote data. We construct a proxy for retail investors' trading intensity, and find that the negative relation between expected returns and the absolute uncertainty beta is significantly stronger for high-retail trading stocks and this effect is highly persistent up to 12 months.

Lastly, we examine the relation between overpricing and sentiment. Stambaugh et al. (2012) document that anomalies are more significant following high-sentiment months, since overpricing is stronger following periods of high sentiment. Using the measure of retail sentiment of Kang et al. (2014), we find that firms with a large absolute uncertainty beta and high retail trading show significantly lower returns only in high-sentiment periods. By contrast, no significant result is observed in low-sentiment periods.

The overall results consistently support the overpricing hypothesis, as opposed to the finding of Bali et al. (2017) supporting the negative premium hypothesis in the US market. In the literature on economic uncertainty, the effects of US economic uncertainty on emerging markets are rarely examined. The literature has actively examined the effects of financial crises in the US stock markets on emerging markets and reported substantial effects (Cha and Oh, 2000; Abd Marjid and Kassim, 2009), but the effects of uncertainty about the US economy on emerging markets have rarely been examined. We expect our paper to contribute to the literature by extending the effects of US economic uncertainty to the other countries' financial markets. Though our paper is motivated by Bali et al. (2017), our paper can be differentiated with Bali et al. (2017) as they investigate the effect of economic uncertainty on the domestic stock market while we focus on the international effect. Previously, Choi and Shim (2019) investigate the impacts of financial and policy uncertainty shocks in six emerging market economies, and find that they show substantial

\footnotetext{
${ }^{2}$ Barber and Odean (2000) and Ofek and Richardson (2003) document that the trading of retail investors seems to be irrational and, therefore, retail trading will limit arbitrage, causing stock prices to deviate far from their efficient prices (Shleifer and Vishny, 1997). Consequently, when more retail investors participate in trading, the negative relation between expected returns and the absolute uncertainty beta will be more significant.
} 
differences from the empirical results in advanced economies. However they examine the impacts of domestic economy's uncertainty on the domestic stock market while we examine the impact of US economic uncertainty on the emerging market. Choi (2018) also examines the impact of the US financial uncertainty shock, which is measure by the volatility index (VIX), on the emerging economies and reports the substantial impacts. However, as Jurado et al. (2017) argue that the VIX and their economic uncertainty index contain different information contents, we expect that this paper would extend the literature.

Our paper also contributes to the literature by suggesting explanations for the different pricing effects in the US and Korean stock markets. We find that the absolute uncertainty beta is strongly correlated with a proxy for the lottery-like characteristic MAX. Retail investors participate a great deal in the Korean market, as opposed to the US market, and the literature documents that retail investors tend to more suffer from under-diversification and thus exhibit a preference for lottery-like assets (Han and Kumar, 2008; Bali et al., 2011). The difference in the empirical results between the US and Korean markets - the findings of Bali et al. (2017) supporting the negative premium hypothesis and our findings supporting the overpricing hypothesis - could stem from that difference.

The remainder of the paper is organized as follows. Section 2 addresses our main hypotheses and Section 3 describes our data and methodology. Section 4 presents our empirical results on pricing effects of economic uncertainty. Next, based on consistent support for our overpricing hypothesis in Section 4, in Section 5 , we further investigate overpricing hypothesis. Section 5 concludes the paper.

\section{Uncertainty and expected returns}

According to Jurado et al. (2015), uncertainty can be generally defined as "the conditional volatility of a disturbance that is unforecastable from the perspective of economic agents." From the point of view of 
traditional finance, economic uncertainty has drawn a great deal of attention, because of its possible role as a state variable in Merton's (1973) intertemporal CAPM. Merton's intertemporal CAPM state variables are associated with changes in consumption and investment opportunities and are thus priced in markets. Since there is increasing evidence in the literature supporting the relation between changes in the conditional volatility of macroeconomic shocks and asset returns (Bloom, 2009; Jurado et al., 2015), economic uncertainty seems to be a rational state variable. Moreover, in terms of investors' preferences, economic uncertainty can be included in their utility function in addition to the mean and variance of returns, because the state of the economy would affect the distribution of future returns and we can thus also expect it to have a significant pricing effect. Bali et al. (2017) provide empirical evidence that economic uncertainty is negatively priced in the US stock market, which is consistent with these ideas on uncertainty. If Korean market investors fear the uncertainty of the US economy as do US market investors, then the negative premium on uncertainty of the US economy will also be observed in the Korean stock market. We call this hypothesis the negative premium hypothesis.

On the other hand, previous studies on the CAPM find that high-market beta stocks tend to have lower future returns than low-market beta stocks, which contradicts the CAPM (Baker et al., 2011; Frazzini and Pedersen, 2014). Hong and Sraer (2016) explain this phenomenon with overpricing. They suggest that highmarket beta stocks are prone to be overpriced. More specifically, given high disagreement among investors about the stock market's prospects, high-beta stocks that are more sensitive to this disagreement will be exposed to a greater divergence of opinions and overpricing due to short-sale constraints will consequently occur. Miller (1977) argues that stocks can be overpriced under a divergence of opinions and limits to arbitrage and, according to Hong and Sraer's (2016) model, high-beta stocks are more exposed to divergences of opinions and are thus more likely to be overpriced. Hong and Sraer's (2016) empirical results show that high-market beta stocks have significantly lower expected returns and this effect is more significant when market disagreement levels are high. 
Our second hypothesis on the relation between economic uncertainty and expected stock returns is closely related to Hong and Sraer's (2016) model. Hong and Sraer's (2016) model assumes that the market beta is proportional to sensitivity to an unobservable common factor of firms' cash flows and thus firms with large market betas experience overpricing because of the divergence of opinions. Specifically, they state that speculative trading on these firms causes overpricing and thus results in lower future returns. Motivated by Hong and Sraer (2016), we assume that speculative trading can exist in firms whose returns are either positively or negatively highly sensitive to economic uncertainty and these firms can therefore be overpriced. Hong and Sraer (2016) assume that their (market) beta ranges from zero and one and, indeed, their data support this assumption. By contrast, the economic uncertainty beta we use is symmetrically distributed around zero, ranging about from -1 to one. Our empirical results show that it ranges from -0.95 to 1.03 and Bali et al. (2017) also report that their uncertainty beta ranges from -0.62 to 0.72 (Table 1). Thus, Hong and Sraer (2016) consider speculative trading only in positively high-beta stocks, since their beta ranges from zero to one, but we can consider speculative trading in stocks with either a positively or negatively high uncertainty beta, since our beta ranges from -1 to one. Consequently, as opposed to the negative premium hypothesis, this explanation expects an inverted $U$ of expected returns across uncertainty betas. We call this hypothesis as the overpricing hypothesis.

\section{Data and methodology}

As a proxy for US economic uncertainty, we use the economic uncertainty index of Jurado et al. (2015). They provide a factor-based estimate of US economic uncertainty based on a comprehensive set of macroeconomic variables. They suggest that their measure is distinctive from the other variables, such as measures of dispersion or stock market volatility, to the point that these other measures could be more closely associated with time-varying risk aversion rather than economic uncertainty. One-, three-, and 12- 
month-ahead economic uncertainty indexes can be obtained from Sydney Ludvigson's website. ${ }^{3}$ In our analysis, we mainly use the one-month-ahead index (UNC) following Bali et al. (2017).

We use Korean stock market data, obtained from FnGuide, that comprise daily and monthly returns on common stocks listed in the Korea Exchange, with a sample period from January 1992 to June 2017. In each month and for each sample stock, we estimate the uncertainty beta $\left(\beta^{U N C}\right)$ from the monthly rolling regression of excess stock returns on UNC over the past 60 months. In estimating the uncertainty beta, we also include Pastor and Stambaugh's (2003) liquidity (LIQ), Fama and French's (2015) five factorsmarket (MKT), size (SMB), value (HML), profitability (RMW), and investment (CMA) factors-and Carhart's (1997) momentum (UMD) factor, as follows:

$$
\begin{gathered}
R_{i, t}=\alpha_{i, t}+\beta_{i, t}^{U N C} U N C_{t}+\beta_{i, t}^{M K T} M K T_{t}+\beta_{i, t}^{S M B} S M B_{t}+\beta_{i, t}^{H M L} H M L_{t}+\beta_{i, t}^{R M W} R M W_{t} \\
+\beta_{i, t}^{C M A} C M A_{t}+\beta_{i, t}^{U M D} U M D_{t}+\beta_{i, t}^{L I Q} L I Q_{t}+\varepsilon_{i, t}
\end{gathered}
$$

We use the Fama-French five factors - the MKT, SMB, HML, RMW, and CMA factors-based on the accounting data from FnGuide following the methodology of Fama and French (2015). For the risk-free rate, we use the one-year monetary stabilization bond rate, following Kim and Shin (2006) and Jang et al. (2012). In computing the risk-adjusted return (alpha) of $\beta^{U N C}$-sorted portfolios, we use four models, following Bali et al. (2017). Specifically, we employ a five-factor model including MKT, SMB, HML, UMD, and LIQ; Fama and French's (2015) five-factor model; a four-factor model including MKT, SMB, RMW, and CMA; and a seven-factor model including MKT, SMB, HML, UMD, RMW, CMA, and LIQ. The resulting alphas are denoted $\alpha_{5}^{1}, \alpha_{5}^{2}, \alpha_{4}$, and $\alpha_{7}$, respectively.

For the cross-sectional analysis, we include market beta $\left(\beta^{M K T}\right)$, firm size (SIZE), the book-to-market ratio (BM), momentum (MOM), short-term reversal (REV), the coskewness (COSKEW), Amihud's (2002)

\footnotetext{
${ }^{3}$ See https://www.sydneyludvigson.com.
} 
illiquidity measure (ILLIQ), the annual growth rate of total assets (I/A), the annual operating profitability (ROE), and the lottery-like property of a stock (MAX). ${ }^{4}$ The Korean stock market is well known for its heavy participation of retail investors ${ }^{5}$ and, according to Han and Kumar (2008) and Bali et al. (2011), retail investors tend to more suffer from under-diversification and thus exhibit a preference for lottery-like assets. We expect MAX to play an important role in estimating expected returns in the Korean stock market.

In Sections 4.4 and 4.5, we use transaction and quote data to investigate the effects of retail investors on the relation between the uncertainty beta and expected returns. ${ }^{6}$ Our data contain a time-ordered record of every stock transaction on the Korea Exchange and information regarding the types and order numbers of buyers and sellers, which enables us to clearly identify the initiator of each trade without employing the Lee-Ready (1991) algorithm. We define the initiator of a trade between a buyer and a seller as the trader who placed the later order of the two, following the chronological definition of Odders-White $(2000)^{7}$ instead of using the Lee-Ready algorithm, which is reported to have misclassification problems (Ellis et al., 2000; Odders-White, 2000; Asquith et al., 2010; Chakrabarty et al., 2012). Using the order submission number of the buyer and seller of each transaction, we can determine who placed the order later.

Our intraday data also provide information about whether the buyer or seller is a domestic individual investor, a domestic institutional investor, or a foreign investor. In Section 4.4, using this trader type information, we construct a proxy for the retail investors' trading intensity, or the RTP (Brandt et al., 2009). For each stock in each month, this measure is computed as the total retail trading volume (sum of buyer-

\footnotetext{
4 See the Supplementary Material for details (available online).

${ }^{5}$ For example, Choe et al. (2005) report that, in $1998,77.43 \%$ of the gross value of stock sales was made by domestic individual investors and trading by the government and corporations represented only a small fraction of the overall trading.

${ }^{6}$ In this analysis, our sample period is restricted to the period from January 2006 to November 2014, due to the availability of the data.

${ }^{7}$ Odders-White (2000) describes the initiator of a transaction as the person who caused the transaction to occur and thus defines an initiator is a trader who placed his or her order last, chronologically. Our data provide the order submission numbers of the buyer and seller of each transaction, so we can determine who placed the order later.
} 
and seller-initiated trades by retail investors) divided by the total trading volume. In Section 4.5 , we construct the retail sentiment measure suggested by Kang et al. (2014). To construct retail sentiment, we first compute the cross-sectional average of the retail buy-sell imbalance and institutional buy-sell imbalance in each month. The monthly retail (institutional) buy-sell imbalance for each stock is defined as the difference in trading volume between buyer- and seller-initiated retail (institutional) trades divided by total retail (institutional) trading volume. Since information about trader type is not generally available, Brandt et al. (2009) proxy for trader type by trade size, as in previous studies (Hvidkjaer, 2008; Barber et al., 2009). However, Lee and Radhakrishna (2000) document that errors from using trade size as a proxy for trader type in the US market. Since our data set provides accurate information, our research is free from the trader type identification issue.

\section{Pricing effects of economic uncertainty}

\subsection{Univariate portfolio-level analysis}

We first examine the relation between the uncertainty beta and expected returns. We investigate which one of the two competing hypotheses in Section 2, the negative premium hypothesis or the overpricing hypothesis, is supported by the empirical evidence. Since the two hypotheses predict the different relations between the uncertainty beta and the expected return, a simple univariate portfolio analysis will be sufficiently informative to compare them. Specifically, we sort our sample stocks by two measures: the

uncertainty beta and the absolute uncertainty beta. According to the negative premium hypothesis, future returns on the portfolio would monotonically decrease as the uncertainty beta increases. By contrast, the overpricing hypothesis suggests an inverted U-shaped pattern of future returns across uncertainty betas and thus a monotonic pattern if we sort stocks by the absolute uncertainty beta. 
[Insert Table 1 here]

First, we sort our sample stocks by their uncertainty betas $\left(\beta^{U N C}\right)$. For each month, decile portfolios are formed by sorting individual stocks by their $\beta^{U N C}$ values. Decile 1 (denoted Low) contains stocks with the lowest $\beta^{U N C}$ values and decile 10 (denoted High) contains stocks with the highest.

Table 1 shows that the estimated uncertainty betas are almost symmetrically distributed around zero. For example, the fifth and sixth decile portfolios have $\beta^{U N C}$ values of -0.05 and 0.05 , respectively and the fourth and seventh decile portfolios have $\beta^{U N C}$ values of -0.16 and 0.17 , respectively. The notable feature is that the lowest and highest decile portfolios show a large distance from the second lowest and highest decile portfolios, respectively. From the ninth (second) decile portfolio, $\beta^{U N C}$ of the highest (lowest) decile portfolio increases (decreases) by $0.54(0.48)$, which is about double the ninth (second) decile portfolio's beta. More importantly, the returns on these $\beta^{U N C}$-sorted portfolios generally show an inverted U-shaped pattern, regardless of whether the returns are risk adjusted. The difference in returns between the high- and low-beta portfolios is even insignificant in all cases $(t$-statistics $=-1.56$ to -0.3$)$. These results are consistent with the overpricing hypothesis.

[Insert Table 2 here]

[Insert Figure 1 here]

To examine the overpricing hypothesis more directly, we sort stocks by the absolute uncertainty betas $\left(\left|\beta^{U N C}\right|\right)$ as we form the $\beta^{U N C}$-sorted portfolios in Table 1. In Table 2, as expected, the $\left|\beta^{U N C}\right|$-sorted portfolios generally show a more clearly decreasing pattern in returns as $\left|\beta^{U N C}\right|$ increases. In other words, firms with positively or negatively large $\beta^{U N C}$ values have significantly lower future returns. In terms of raw excess returns (RET-RF), the differences between the high and low portfolios appear to be negative but statistically insignificant in both the equal- and value-weighted cases. In terms of risk-adjusted returns, however, two of the four alphas $\left(\alpha_{5}^{1}\right.$ and $\left.\alpha_{7}\right)$ show significant results in the equal-weighted cases and all 
alphas show significant results in the value-weighted cases. The differences in risk-adjusted returns are negatively much larger and more significant in the value-weighted cases than in the equal-weighted cases. The average monthly returns range from $-1.12 \%$ to $-1.44 \%$ and the $t$-statistics range from -2.18 to -2.81 . To clearly see the differences in returns across the uncertainty beta-sorted portfolios in Table 1 and the absolute uncertainty beta-sorted portfolios in Table 2, we plot the risk-adjusted returns $\left(\alpha_{5}^{1}\right)$ across portfolios in Figure 1. Our results from the portfolio analysis thus clearly support the overpricing hypothesis and reject the negative premium hypothesis.

In sum, our results indicate that the expected returns monotonically increase as the absolute uncertainty beta increases. By contrast, the expected returns show no notable pattern if we sort stocks by the uncertainty beta. Between the two possible predictions of the relation between the uncertainty beta and expected returns, our empirical results support the overpricing hypothesis, which predicts an inverted U-shaped pattern in returns across uncertainty betas.

\subsection{Stock characteristics}

In this section, we investigate the average characteristics of stocks according to their uncertainty betas. We first examine the characteristics of $\beta^{U N C}$-sorted portfolios. Then, as we find the monotonic relation between $\left|\beta^{U N C}\right|$ and returns in the previous section, we regress $\left|\beta^{U N C}\right|$ on a set of characteristics. We report the results from the former and latter tests in Panels A and B, respectively, of Table 3.

[Insert Table 3 here]

In Panel A of Table 3, we can see that many characteristics exhibit a U-shaped pattern or an inverted U-shaped pattern across $\beta^{U N C}$ values as the expected returns in Table 2. For example, $\beta^{M K T}$, MOM, ILLIQ, I/A, and MAX tend to be higher for firms with a positively or negatively large uncertainty beta. These results indicate that firms that are highly sensitive to economic uncertainty tend to have higher market risk, past returns, and investment and lower liquidity. They also tend to be more lottery-like. On the other hand, 
SIZE and BM exhibit an inverted U-shape across the $\beta^{U N C}$-sorted portfolios. While the pattern for SIZE seems to be rather weak, the lowest and highest $\beta^{U N C}$ decile portfolios have smaller firm sizes and lower book-to-market ratios than the others. Only REV and COSKEW monotonically increase as $\beta^{U N C}$ increases and ROE seems to have no specific pattern. The average stock characteristics of $\beta^{U N C}$-sorted portfolios thus show that the lowest- and highest- $\beta^{U N C}$ stocks have similar characteristics and, thus, we further examine their relations by regressing $\left|\beta^{U N C}\right|$ on a set of stock characteristics.

Panel B of Table 3 presents the results from regressing $\left|\beta^{U N C}\right|$ on a set of characteristics in Panel A. In Models (1) to (10), we regress $\left|\beta^{U N C}\right|$ on each characteristic and, in Model (11), we include all stock characteristics in the regression. First, all characteristic variables have a consistent relation with $\left|\beta^{U N C}\right|$ in the univariate and multivariate regressions. The signs of the coefficients of a variable in the univariate and multivariate models are the same and their statistical significance shows only a small change. For example, Models (3) and (11) show that the coefficients of BM are -0.093 and -0.098 , with $t$-statistics -7.24 and 7.69, respectively. Moreover, $\beta^{M K T}$, MOM, I/A, and MAX show significantly positive relations with $\left|\beta^{U N C}\right|$ in Panel B and these features are consistent with the U-shaped relation with $\beta^{U N C}$ in Panel A. Considering that high- $\left|\beta^{U N C}\right|$ stocks have lower returns, the positive relation with $\beta^{M K T}$ seems to be consistent with the results of Frazzini and Pedersen (2014) and Hong and Sraer (2015), indicating that high$\beta^{M K T}$ stocks have lower returns. The negative relations with BM, ILLIQ, and ROE and the positive relations with I/A are also consistent with the literature, in that stocks with a low book-to-market ratio, low illiquidity (high liquidity), low profitability, and high investment have lower expected returns (Amihud, 2002; Fama and French, 2015).

Panel B of Table 3 shows a very interesting and highly significant relation between MAX and $\left|\beta^{U N C}\right|$. This indicates that stocks highly sensitive to economic uncertainty could have lottery-like characteristics that could appeal to retail or noise investors. Our results are in great contrast to the results of Bali et al. (2017). In the US market, Bali et al. (2017) find that MAX does not have a significant relation with $\beta^{U N C}$ 
$(t$-statistics $=1.30)$ if other effects are controlled for, but our results show that its effect is strongly persistent, even after controlling for other variables $(t$-statistics $=7.63)$. As we document in Section 3, retail investors are major participants in the Korean market, unlike the US market, and the different empirical results from the US and Korean markets - the findings of Bali et al. (2017) supporting the negative premium hypothesis and our findings supporting the overpricing hypothesis - could thus stem from this difference.

\subsection{Cross-sectional analysis}

The portfolio analysis sorting by a characteristic has the advantage of being a nonparametric analysis, but its disadvantage is that it is difficult to control for the effects of various variables simultaneously. Thus, in this section, in each month, we run the following Fama-MacBeth (1973) cross-sectional regression:

$$
R_{i, t+1}=\gamma_{0, t}+\gamma_{1, t}\left|\beta_{i, t}^{U N C}\right|+\gamma_{2, t} X_{i, t}+\varepsilon_{i, t+1}
$$

where $R_{i, t+1}$ indicates the return on stock $i$ in month $t+1$ and $\left|\beta_{i, t}^{U N C}\right|$ indicates the absolute value of the uncertainty beta for stock $i$ in month $t$, as estimated by Eq. (1). The term $X_{i, t}$ indicates a set of firm-specific control variables for stock $i$ on month. ${ }^{8}$

\section{[Insert Table 4 here]}

In Models (1) to (4) of Table 4, our results show that the coefficients of $\left|\beta^{U N C}\right|$ are significant and even robust to the control variables. We also report the results for the uncertainty beta $\left(\beta^{U N C}\right)$ in Table S2 of the Supplementary Material (available online) but, even in the univariate regression model (Model (1)), $\beta^{U N C}$ shows no significant relation with expected returns. ${ }^{9}$

\footnotetext{
${ }^{8}$ Overall in this paper, we estimate Fama-MacBeth regressions using the value-weighted linear regression method with the market capitalization of a stock as the weight. We confirm that the equal-weighted and value-weighted results are the qualitatively same, and thus we report only the value-weighted results.

${ }^{9}$ We appreciate an anonymous referee to suggest to additionally consider the lagged uncertainty index in estimating uncertainty beta in Eq.(1). We estimate the uncertainty beta using the lagged uncertainty index and examine its pricing
} 
In Model (5) of Table 4, however, the coefficient of $\left|\beta^{U N C}\right|$ shows a substantial decrease (coefficient $=-0.005)$ as MAX is additionally controlled. In the previous section, we find that $\left|\beta^{U N C}\right|$ is closely associated with MAX. This could also imply that investors' preference for lottery-like stocks is related to speculative trading on stocks that are highly sensitive to economic uncertainty. The coefficient of MAX in Model (5) is negatively large and significant (coefficient $=-0.429$ and $t$-statistics $=-6.87$ ) and its effect substantially reduces the marginal effect of $\left|\beta^{U N C}\right|$. Even after controlling for the effect of MAX, however, our results suggest that $\left|\beta^{U N C}\right|$ still has significant explanatory power for the expected return. In other words, though speculative trading on high- $\left|\beta^{U N C}\right|$ stocks could be related to trading based on lottery-like preferences, the pricing effect of $\left|\beta^{U N C}\right|$ is not totally subsumed by that of MAX. The coefficients of $\left|\beta^{U N C}\right|$ are significant at the $10 \%$ level, with $t$-statistics of -1.81 .

Next, we examine whether consistent results are observed in the long term as well. Bali et al. (2017) examine the long-term predictive power of the uncertainty beta and provide evidence that the negative premium hypothesis is strongly supported in the US stock market, even in the long-term. They report that the coefficients of $\beta^{U N C}$ remain significantly negative for returns up to 11 months ahead. Using Model (5) in Table 3, which includes all the controlling variables, we regress the $n$-month-ahead returns on the set of explanatory variables for $n=2, \ldots, 12 .^{10}$

\section{[Insert Table 5 here]}

Table 5 shows that $\left|\beta^{U N C}\right|$ generally has significant and negative coefficients. The exceptions are concentrated in the intermediate horizon, where $n=5, \ldots, 8$, but no variable shows a significant relation with future returns in these cases. Moreover, we find that the coefficients of $\left|\beta^{U N C}\right|$ in Table 5 are more

effect. We replicate Table S2 and Table 4 with this newly estimated uncertainty beta, and confirm consistent findings. More specifically, we find that the uncertainty beta is not significantly priced while the uncertainty absolute beta shows highly significant and negative pricing effect.

${ }^{10}$ We additionally report the results for $\beta^{U N C}$ in Table S3 in the Supplementary Material (available online) for comparison. 
significant than those in the one-month-ahead return case in Table 4, regardless of the weighting scheme in the regressions.

In many cases, MAX also shows consistently strong predictive power, but its pricing effect appears to be stronger in the short term (Table 4) than in the long term (Table 5), as opposed to the coefficients of $\left|\beta^{U N C}\right|$. For example, among the significant cases, MAX shows a (negatively) largest coefficient (-0.259) in the two-month-ahead case, but a much smaller one than for the one-month-ahead case, which is -0.429 . These results suggest that, in the short term, MAX and $\left|\beta^{U N C}\right|$ could contain common information, whereas, in the long term, it seems that their effects are more distinctive and thus the predictive power of $\left|\beta^{U N C}\right|$ appears to be more significant, even after controlling for MAX.

To summarize, consistent with the previous sections, we find that $\left|\beta^{U N C}\right|$ is significantly and negatively priced, even after we control for other firm characteristics, while $\beta^{U N C}$ shows insignificant results. Moreover, the significant price impact of $\left|\beta^{U N C}\right|$ appears to persist for up to 12 months, although there are exceptions in the intermediate term. These results are consistent with the overpricing hypothesis, which indicates that stocks that are highly sensitive to economic uncertainty either positively or negatively could experience a greater divergence of opinions and are therefore more likely to be overpriced.

\subsection{Robustness check}

We further perform two robustness tests ${ }^{11}$ on the pricing effect of the US economic uncertainty on the Korean stock market. First, we control the effect of the Korean economic uncertainty and investigate whether previous findings are robust to it. Specifically, we additionally include the Korean uncertainty index constructed by Shin et al. (2018) ${ }^{12}$ in Eq. (1) to estimate the marginal effects of the US economic

\footnotetext{
${ }^{11}$ We appreciate an anonymous referee to suggest robustness tests using the Korean uncertainty index and the VIX.

${ }^{12}$ The Korean economic uncertainty index constructed by Shin et al. (2018) is provided as Appendix A. Supplementary
} 
uncertainty $\left(\beta^{U N C}\right)$ and the Korean economic uncertainty $\left(\beta^{K U N C}\right)$. Next, we include both the US and Korean economic uncertainty (absolute) betas in our cross-sectional regression model. We replicate Table S2 and Table 4 with the US and Korean economic uncertainty betas, and report the pricing effects of the US and Korean economic uncertainty betas and absolute betas in Panels A and B of in Table S4 (See Supplementary Material, available online), respectively. We find that while both betas and absolute betas of the Korean economic uncertainty index are not significantly priced, the US economic uncertainty beta is significantly and negatively priced even after controlling for the effect of Korean economic uncertainty. Though it becomes insignificant $(t$-statistics $=-1.45)$ after controlling for the effect of MAX (Model (5) in Panel B), overall results provide the qualitatively similar results. ${ }^{13}$

Second, we employ the VIX ${ }^{14}$ as an alternative proxy for US economic uncertainty and examine whether it shows consistent results. Though Bekaert et al. (2013) document that the VIX is largely associated with time-varying risk-aversion rather than economic uncertainty, the VIX is one of the most popular proxies for uncertainty (Bloom, 2009) and thus it is worthy enough to examine the effect of economic uncertainty on commodity futures markets with the VIX as an alternative to the uncertainty index. We estimate the VIX beta as we estimate the uncertainty beta using Eq. (1), and replicate Table S2 and Table 4 with the VIX betas. In Table S5 (See the Supplementary Material, available online), we confirm the consistent results with the VIX. More specifically, we find that the VIX beta is not significantly priced while the VIX absolute beta shows highly significant and negative pricing effect.

data (https://doi.org/10.1016/j.econlet.2017.10.014). The data span the period from October 1991 to May 2016. ${ }^{13}$ In untabulated results, we also replicate Table 11 with additional two variables, Korean absolute uncertainty beta $\left(\left|\beta^{K U N C}\right|\right)$ and the interaction of the Korean absolute uncertainty beta and high RTP dummy $\left(\left|\beta^{K U N C}\right| \times \mathrm{H}\right)$. We find that if we additionally consider limit to arbitrage which is measured by retail trading, then stocks with high US uncertainty absolute betas show significantly lower returns when limit to arbitrage is high while stocks with high Korean uncertainty absolute betas show no significant results.

${ }^{14}$ We use the old version of the VIX which is called VXO as it provides the longer sample period. The VIX index provided by CBOE measures the implied volatility of the at-the-money options on the S\&P100 index. 


\section{Overpricing hypothesis}

\subsection{Retail trading as limits to arbitrage}

From Sections 4.1 to 4.3 , we find that our empirical results provide consistent support for the overpricing hypothesis, which argues that high- $\left|\beta^{U N C}\right|$ stocks are more likely to be overpriced because of greater divergence of opinions. According to this hypothesis, however, such overpricing can occur only if

limits to arbitrage exist. Our results consistently suggest that speculative trading on high- $\left|\beta^{U N C}\right|$ stocks causing overpricing seems to be closely related to a lottery-like preference, which retail investors could have. Therefore, in this section, we consider the trading of retail investors as possible limits to arbitrage in the Korean stock market and conduct further analysis to determine whether overpricing exists for firms that are highly sensitive to economic uncertainty and which also have larger retail trading. According to Han and Kumar (2008) and Bali et al. (2011), the trading of retail investors can be considered a proxy for lotterylike preferences, as well as a proxy for limits to arbitrage. Nagel (2005) argues that the level of institutional ownership can be a good proxy for the ease of short sales. Since the main suppliers of stock loans are institutional investors (D'Avolio, 2002), short sales are more constrained for stocks with low levels of institutional trading or high levels of retail trading. In addition, Barber and Odean (2000) and Ofek and Richardson (2003) document that the trading of retail investors seems to be irrational and thus their trading limits arbitrage. Kang and Sim (2014) also document that the MAX effect is stronger among stocks with high levels of retail trading and Kang et al. (2014) find that high levels of retail trading limit arbitrage more severely. Based on these findings, we expect that the negative relation between expected returns and $\left|\beta^{U N C}\right|$ will be stronger when more retail investors participate in trading.

Utilizing our unique transaction and quote data on the Korean stock market (more details in Section 3), we construct the RTP, following Brandt et al. (2009), and perform two analyses with it: a portfolio analysis and a cross-sectional analysis. First, we construct independently double-sorted portfolios. We sort 
sample stocks by the RTP into three groups and independently sort stocks by $\left|\beta^{U N C}\right|$ into 10 groups. We compute the equal- and value-weighted returns on each portfolio and the long-short portfolio, such as the high RTP - low RTP portfolio and high $\left|\beta^{U N C}\right|$ - low $\left|\beta^{U N C}\right|$ portfolio, to see whether the return difference is significant. The average excess returns (RET-RF) and risk-adjusted returns $\left(\alpha_{5}^{1}, \alpha_{5}^{2}, \alpha_{4}\right.$, and $\left.\alpha_{7}\right)$ are computed for the equal- and value-weighted portfolios separately, but we report only value-weighted results for brevity as they are qualitatively similar.

\section{[Insert Table 6 here]}

In Table 6 , the return difference between high- and low- $\left|\beta^{U N C}\right|$ stocks is substantially large and significant within the high-retail trading group (RTP3). The portfolio with the highest levels of retail trading and the greatest $\left|\beta^{U N C}\right|$ (highest $\left|\beta^{U N C}\right|$ decile in RTP3) exhibits notably low returns in all cases, a feature that is consistent with the overpricing hypothesis. Stocks that are more likely subject to a greater divergence of opinion (high $\left|\beta^{U N C}\right|$ ) and limits to arbitrage (high level of retail trading) show lower future returns. On the other hand, the portfolio with the lowest levels of retail trading and smallest $\left|\beta^{U N C}\right|$ (lowest $\left|\beta^{U N C}\right|$ decile in RTP1) generally shows high returns, but not the highest. For example, the highest $\left|\beta^{U N C}\right|$ decile in the RTP3 group has a return of $-1.99 \%$ while the returns on the other 29 portfolios range from $-1.30 \%$ to $1.12 \%$. Among these, the return on the lowest $\left|\beta^{U N C}\right|$ decile in the RTP1 group is $0.62 \%$, which is large, but not the largest.

More importantly, the return difference between the high- and low-beta portfolios (high $\left|\beta^{U N C}\right|$ - low $\left.\left|\beta^{U N C}\right|\right)$ appears to be significant only if there is a high level of retail trading (RTP3). The alphas are all negatively significant at the $1 \%$ level $(t$-statistics $=-3.77$ to -3.54$)$ and these differences in alphas between high and low $\left|\beta^{U N C}\right|$ portfolios seem to be driven by the notably low returns on high- $\left|\beta^{U N C}\right|$ stocks. On the other hand, in the low-retail trading group (RTP1), the high $\left|\beta^{U N C}\right|-$ low $\left|\beta^{U N C}\right|$ portfolios generate insignificant returns in all cases. . That is, we find consistent and strong evidence supporting the overpricing 
hypothesis, which implies that stocks with high sensitivity to economic uncertainty and high limits to arbitrage generate lower returns than other stocks do.

In Table 6, we can see another interesting pattern from the returns on the RTP 3-1 portfolios. The return difference between the high- and low-RTP portfolios is insignificant in the low- $\left|\beta^{U N C}\right|$ group, but becomes negatively significant as $\left|\beta^{U N C}\right|$ increases. It becomes even more significant if the other factors are controlled for. These results imply that the effects of $\left|\beta^{U N C}\right|$ and the RTP are not redundant to each other and the lower return is generated when both $\left|\beta^{U N C}\right|$ and the RTP are jointly affected. According to the overpricing hypothesis based on Miller's (1977) explanation for overpricing, stocks will be overpriced if a divergence of opinions exists in the market, especially when arbitrage is limited. Since the divergence of opinions captured by speculative trading on high- $\left|\beta^{U N C}\right|$ stocks (Hong and Sraer, 2016) and the RTP is related to limits to arbitrage (Barber and Odean, 2000; Ofek and Richardson, 2003), our results seem to be consistent with Miller's (1977) explanation that overpricing occurs when the two conditions are jointly binding.

Next, we perform Fama-MacBeth (1974) cross-sectional regressions using a dummy variable for retail trading. We construct a dummy variable $H$ that has the value of one if the RTP of a stock is larger than the 70th percentile of all the KOSPI stocks' RTPs and zero otherwise. We use the KOSPI breakpoint because retail investors are highly concentrated in the KOSDAQ market and we therefore want to avoid bias toward the KOSDAQ market if we include them to determine the breakpoint for high-retail trading firms. With Eq. (2), we further include the interaction term of $\left|\beta^{U N C}\right|$ and $H$, as in Eq. (3), to see whether the high-retail trading group shows significant difference:

$$
R_{i, t+1}=\gamma_{0, t}+\gamma_{1, t}\left(\left|\beta_{i, t}^{U N C}\right| \times H_{i, t}\right)+\gamma_{2, t}\left|\beta_{i, t}^{U N C}\right|+\gamma_{3, t} X_{i, t}+\varepsilon_{i, t+1}
$$


Based on our previous findings, we can predict that the coefficient of the interaction term $\left(\gamma_{1}\right)$ will be significantly negative, since it indicates that the negative relation between the absolute uncertainty beta and future returns is more pronounced among the high-retail trading group.

\section{[Insert Table 7 here]}

In Table 7, the coefficients of the interaction term $\left(\gamma_{1}\right)$ are strongly significant and negative both with and without controlling variables. The contrasting results for $\left|\beta^{U N C}\right|$ are noteworthy. Without controlling variables, in Model (1), the coefficients of $\left|\beta^{U N C}\right|\left(\gamma_{2}\right)$ showing the relation between the expected return and the $\left|\beta^{U N C}\right|$ values of low-RTP firms are significant at the $10 \%$ level $(t$-statistics $=-1.80)$. If other characteristic variables are controlled for, however, the coefficients $\left(\gamma_{2}\right)$ become insignificant (Models (2) to (5)). Compared to the coefficients of $\left|\beta^{U N C}\right|$ in Table 4 , the estimated $\gamma_{1}$ is negatively larger and remains significant even in Model (5) of Table 7. In addition, in Model (5) of Table 7, MAX shows significant results, as in Table 4, but does not subsume the effect of $\left|\beta^{U N C}\right|$ for high-retail trading firms.

\section{[Insert Table 8 here]}

Next, as we find the long-term predictability of $\left|\beta^{U N C}\right|$ in Table 5, we extend the cross-sectional analysis of Eq. (3) to long-term future returns. Table 8 provides results consistent with those of Table 7. The coefficients of $\left|\beta^{U N C}\right|$ are not significant in all cases, while those of the interaction term $\left(\left|\beta^{U N C}\right| \times H\right)$ are highly significant, and the value-weighted regressions show stronger results than the equal-weighted regressions $(t$-statistics $=-2.09$ to -2.59$)$. Our results suggest that the persistent negative relation between the absolute uncertainty beta and expected returns is observed only among firms with high levels of retail trading.

Compared to the results in Table 5 that do not consider retail trading, Table 8 provides stronger evidence for the overpricing hypothesis. In Table 5 , we find four exceptions $(n=5, \ldots, 8)$ where the coefficients of $\left|\beta^{U N C}\right|$ are not significant, but Table 8 shows no exceptions if retail trading is considered. 
The negative relation between expected returns and $\left|\beta^{U N C}\right|$ among high-RTP stocks remains significant up to 12 months. Moreover, since the coefficient of $\left|\beta^{U N C}\right| \times H$ in Model (5) of Table 7 is negatively larger than that of $\left|\beta^{U N C}\right|$ in Model (5) of Table 4, the coefficients of $\left|\beta^{U N C}\right| \times H$ are also negatively much larger than those of $\left|\beta^{U N C}\right|$ in Table 5. The results in Table 8 also suggest that the coefficients of $\left|\beta^{U N C}\right|$ are rarely affected by extending the predictive horizon. In the case of $n=2$, the coefficient of the interaction term is -0.014 , with $t$-statistics $=-2.59$, whereas it is -0.012 , with $t$-statistics $=-2.14$, in the case of $n=12$.

To sum up, our results strongly indicate that stocks with high sensitivity to economic uncertainty and high levels of retail trading are more likely to be overpriced and thus generate lower future returns. These results are consistent with Miller's (1977) explanation that there will be overpricing if there exists a divergence of opinions in the market, especially when arbitrage is limited. In addition, the negative relation between expected returns and the absolute uncertainty beta among high-retail trading stocks even appears to be highly persistent, remaining significant up to 12 months.

\subsection{Overpricing and retail sentiment}

Combining Miller's explanation with sentiment, Stambaugh et al. (2012) document that overpricing is stronger following periods of high sentiment. They explain that the most optimistic investors would exert the greatest effect on the stock's price because relatively less optimistic investors would not take positions if they viewed the stock as overvalued. Thus, during high-sentiment periods, the most optimistic views tend to be overly optimistic and overpricing will thus be more prevalent than during low-sentiment periods. In conjunction with our overpricing hypothesis, we can also expect overpricing to be more significant in highsentiment periods and thus the negative relation between expected returns and absolute uncertainty beta becomes more prevalent in these periods. Specifically, since we previously document that retail trading tends to drive overpricing, we especially take into account retail sentiment. 
Since Baker and Wurgler's (2006) version of a sentiment index is not available for the Korean market, Kang et al. (2014) construct a proxy for retail sentiment that captures the buying intensity of retail investors relative to institutional investors, using the following regression:

$$
R B S I_{t}=\alpha_{0}+\alpha_{1} I B S I_{t}+e_{t}
$$

where $R B S I_{t}\left(I B S I_{t}\right)$ is defined as the cross-sectional average of the retail (institutional) buy-sell imbalance in month $t$, where the retail (institutional) buy-sell imbalance for each stock is defined as the difference in trading volume between buyer- and seller-initiated retail (institutional) trades divided by the total retail (institutional) trading volume. In Eq. (4), $e_{t}$ can be interpreted as retail investors' buying intensity relative to that of institution investors. A positive (negative) value then indicates that retail investors have initiated more buys (sells) than institutional investors have. Kang et al. (2014) call the residual $e_{t}$ retail sentiment and define a high-sentiment (low-sentiment) month as one in which the residual of the previous month is positive (negative). Using retail sentiment, they show that the idiosyncratic volatility puzzle in the Korean stock market, which seems to be driven by overpricing, is more prevalent in high-sentiment periods. Dividing the total sample period from January 2006 to November 2014 into two subsamples, one including high-sentiment months and the other one including low-sentiment months, ${ }^{15}$ we construct double-sorted portfolios as in Table 6 in each period. Tables 9 and 10 present the value-weighted returns on the portfolios in the high- and low-sentiment periods, respectively.

[Insert Table 9 here]

[Insert Table 10 here]

Tables 9 and 10 suggest that the results from the whole sample period in Table 6 are mainly driven by high-sentiment periods. In Table 9, in high-sentiment periods, the return difference between high- and low-

\footnotetext{
${ }^{15}$ Consequently, we have 53 high-sentiment months and 54 low-sentiment months.
} 
$\left|\beta^{U N C}\right|$ stocks appears to be large within the highest retail trading group (RTP3). Though the raw excess return (RET-RF) on high $\left|\beta^{U N C}\right|-$ low $\left|\beta^{U N C}\right|$ portfolios with high levels of retail trading appear to be statistically weak, in terms of the alphas, they are all negatively significant at the $1 \%$ level and these differences seem to be attributed to the notably low returns on high- $\left|\beta^{U N C}\right|$ stocks. We also find that the return difference between the high- and low-RTP portfolios is significant only if the stocks have a high absolute uncertainty beta, as in Table 6. Moreover, comparing Tables 6 and 9, we find that the risk-adjusted returns in high-sentiment periods are larger and more significant than those in the whole sample period. By contrast, Table 10 shows that returns on high $\left|\beta^{U N C}\right|-\operatorname{low}\left|\beta^{U N C}\right|$ portfolios with high levels of retail trading are much smaller than in Tables 6 and 9. These results suggest that especially the results in Table 6 are attributed to high-sentiment periods.

Next, we examine the effect of retail sentiment on the relation between expected returns and the absolute uncertainty beta after controlling for other variables with the Fama-MacBeth (1974) crosssectional regression. We estimate Eq. (3) in high- and low-sentiment periods separately and report the results in Panels A and B of Table 11, respectively.

\section{[Insert Table 11 here]}

In Table 11, the relation between expected returns and the absolute uncertainty beta for firms with high levels of retail trading is strikingly different between high- and low-sentiment periods. In high-sentiment periods, the coefficient of $\left|\beta^{U N C}\right| \times H\left(\gamma_{1}\right)$ is highly significant at the $1 \%$ level, even after controlling for all variables. This feature is consistent with the results in Table 7 , but the value of $\gamma_{1}$ is negatively much larger in high-sentiment periods, since it is negatively much smaller and less significant in low-sentiment periods. For example, Model (5) in Panel A of Table 11 shows that $\gamma_{1}$ has a value of -0.026 , whereas it has a value of -0.003 in Panel B. Consequently, within the whole sample period, Model (5) in Table 7 provides a value of -0.014 , which is negatively much smaller than the case of high-sentiment periods. In addition, 
not surprisingly, $\left|\beta^{U N C}\right|$ is insignificant in all cases, in both high- and low-sentiment periods. These results consistently support the overpricing hypothesis.

The effect of MAX on expected returns also appears to be affected by retail sentiment. Though the coefficients of MAX are highly significant in both high- and low-sentiment periods, they are substantially reduced in low-sentiment periods. Specifically, MAX is reduced from -0.453 in high-sentiment periods to -0.280 in low-sentiment periods. These results are also consistent with the literature on retail investors' preferences for lottery-like assets (Han and Kumar, 2008; Bali et al., 2011). According to the definition of retail sentiment in our analysis, high-sentiment periods indicate that retail investors have initiated more buys relative to institutional investors during these periods. Since they prefer lottery-like stocks, the effect of MAX on expected returns can be more prominent during these high-sentiment periods than during lowsentiment periods.

Lastly, as in Tables 5 and 8 , we examine the long-term predictability of $\left|\beta^{U N C}\right|$ in high- and lowsentiment months separately. More specifically, we examine how retail sentiment in the month prior to portfolio construction affects the return on the portfolio $n$ months after construction for $n=2, \ldots, 12$. In Table 12, Panels A and B provide the results in high- and low-sentiment periods, respectively.

[Insert Table 12 here]

Table 12 shows that the negative relation between $\left|\beta^{U N C}\right| \times H$ and expected returns is significant up to 12 months only in high-sentiment periods. In other words, the negative pricing effect of $\left|\beta^{U N C}\right| \times H$ is highly persistent in high-sentiment periods. By contrast, consistent with Table $11,\left|\beta^{U N C}\right|$ does not show any significant impact in either high- or low-sentiment periods. Besides $\left|\beta^{U N C}\right| \times H$, MAX also shows persistent predictability for future returns. This effect appears to be significant in both periods, but the sizes of the coefficients show substantial differences, as in Table 11. The variable MAX shows a negatively much larger impact on future returns in the case of high sentiment. 
Overall, in addition to our previous results, this section provides more empirical evidence supporting the overpricing hypothesis. Previously, we find that overpricing occurs when two conditions - a divergence of opinions captured by speculative trading on high- $\left|\beta^{U N C}\right|$ stocks and limits to arbitrage captured by high levels of retail trading (RTP) — are jointly binding. According to Stambaugh et al. (2012), overpricing is stronger following periods of high sentiment and our results in this section also provide consistent evidence that overpricing is prevalent only in high-sentiment periods.

\section{Conclusion}

In this paper, we examine whether US economic uncertainty is significantly priced in the Korean stock markets. We develop two competing hypotheses, the negative premium hypothesis and the overpricing hypothesis, and empirically examine them in the Korean stock market. Our empirical results provide consistent and concrete evidence for the overpricing hypothesis.

Our results are in stark contrast with those of Bali et al. (2017) in the US stock markets. They find that the negative premium hypothesis is supported in the US markets. We suggest that this difference in results between the study of Bali et al. (2017) and ours stems from different proportions of retail trading in the two markets. Unlike US stock markets, there exists a large proportion of retail trading in the Korean stock markets, and such trading could thus cause overpricing for stocks with a (positively or negatively) high uncertainty beta. Consistent with our expectations, the results suggest that the negative relation between expected returns and the absolute beta is significantly stronger within high-retail trading stocks and that this effect is even highly persistent and remains significant for up to 12 months. Moreover, as Stambaugh et al. (2012) document, we find that the returns on stocks with a large absolute beta and high levels of retail trading are significant only following periods of high sentiment. Overall, the results suggest that largeabsolute beta stocks are more likely to be overpriced. 


\section{References}

Abd Marjid, M.S., and S.H. Kassim. 2009. Impact of the 2007 US financial crisis on the emerging equity markets. International Journal of Emerging Markets 4, 341-357.

Amihud, Y. 2002. Illiquidity and stock returns: Cross-section and time-series effects. Journal of Financial Markets 5, 31-56.

Asquith, P., R. Oman, and C. Safaya. 2010. Short sales and trade classification algorithms. Journal of Financial Markets 13, 157-173.

Baker, M., B. Bradley, and J. Wurgler. 2011. Benchmarks as limits to arbitrage: Understanding the lowvolatility anomaly. Financial Analysts Journal 67, 40-54.

Baker, M., and J. Wurgler. 2006. Investor sentiment and the cross-section of stock returns. Journal of Finance 61, 1645-1680.

Bali, T.G., S.J. Brown, and Y. Tang. 2017. Is economic uncertainty priced in the cross-section of stock returns? Journal of Financial Economics 126, 471-489.

Bali, T.G., N. Cakici, and R. Whitelaw. 2011. Maxing out: Stocks as lotteries and the cross-section of expected returns. Journal of Financial Economics 99, 427-446.

Barber, B.M., and T. Odean. 2000. Trading is hazardous to your wealth: The common stock investment performance of individual investors. Journal of Finance 55, 773-806.

Barber, B.M., T. Odean, and N. Zhu. 2009. Do retail trades move markets? Review of Financial Studies $22,151-186$.

Bekaert, G., M. Hoerva, and M.L. Duca. 2013. Risk, uncertainty and monetary policy. Journal of Monetary Economics 60, 771-788.

Bloom, N. 2009. The impact of uncertainty shocks. Econometrica 77, 623-685.

Brandt, M.W., A. Brav, J.R. Graham, and A. Kumar. 2009. The idiosyncratic volatility puzzle: Time trend or speculative episodes? Review of Financial Studies 23, 863-899.

Brusa, F., P. Savor, and M. Wilson. 2017. One central bank to rule them all. SSRN Working paper

Carhart, M.M. 1997. On persistence in mutual fund performance. Journal of Finance 52, 57-82.

Cha, B., and S. Oh. 2000. The relationship between developed equity markets and the Pacific Basin's emerging equity markets. International Review of Economics and Finance 9, 299-322.

Chakrabarty, B., P.C. Moulton, and A. Shkilko. 2012. Short sales, long sales, and the Lee-Ready trade classification algorithm revisited. Journal of Financial Markets 15, 467-491.

Choe, H., B.-C. Kho, and R.M. Stulz. 2005. Do domestic investors have an edge? The trading experience of foreign investors in Korea. Review of Financial Studies 18, 798-829. 
Choi, S. 2018. The impact of US financial uncertainty shocks on emerging market economies: An international credit channel. Open Economies Review 29, 89-118.

Choi, S., and M. Shim. 2019. Financial cs. Policy uncertainty in emerging market economies. Open Economies Review 30, 297-318.

D’Avolio, G. 2002. The market for borrowing stock, Journal of Financial Economics 66, 271-306.

Ellis, K., R. Michaely, and M. O’Hara. 2000. The accuracy of trade classification rules: Evidence from Nasdaq. Journal of Financial and Quantitative Analysis 35, 529-551

Fama, E.F., and K.R. French. 1992. Cross-section of expected stock returns. Journal of Finance 47, 427465 .

Fama, E.F., and K.R. French. 2015. A five-factor asset pricing model. Journal of Financial Economics $116,1-22$.

Fama, E.F., and J. MacBeth. 1973. Risk, return and equilibrium: Empirical tests. Journal of Political Economy 51, 55-84.

Frazzini, A., and L.H. Pedersen. 2014. Betting against beta. Journal of Financial Economics 111, 1-25.

Han, B., and A. Kumar. 2008. Retail clienteles and the idiosyncratic volatility puzzle. Working paper, University of Texas at Austin.

Hong, H., and D.A, Sraer. 2016. Speculative betas. Journal of Finance 71, 2095-2144.

Hvidkjaer, S. 2008. Small trades and the cross-section of stock returns. Review of Financial Studies 21, $1123-1151$

Jang, J., J. Kang, and C. Lee. 2012. Liquidity risk and expected stock returns in Korea: A new approach. Asia-Pacific Journal of Financial Studies 41, 704-738.

Jurado, K., S.C. Ludvigson, and S. Ng. 2015. Measuring uncertainty. American Economic Review 105, $1177-1216$.

Kang, J., E. Lee, and M. Sim. 2014. Retail investors and idiosyncratic volatility puzzle: Evidence in the Korean stock market, Asia-Pacific Journal of Financial Studies 43, 516-547.

Kang, J., and M. Sim. 2014. Lottery-like stocks and the cross-section of expected stock returns in the Korean stock market, Asian Review of Financial Research 27, 297-332.

Kim, D., and S. Shin. 2006. The risk of earnings information uncertainty and the January effect in Korean stock markets, Asia-Pacific Journal of Financial Studies 35, 71-102

Lee, C.M.C., and B. Radhakrishna. 2000. Inferring investor behavior: Evidence from TORQ data. Journal of Financial Markets 3, 83-111.

Lee, C.M.C., and M.J. Ready. 1991. Inferring trade direction from intraday data. Journal of Finance 46, 733-746. 
Makarova, S. 2014. Risk and uncertainty: Macroeconomic perspective. Working paper, University of College London, UK.

Merton, R.C. 1973. An intertemporal capital asset pricing model. Econometrica 41, 867-887.

Miller, E.M. 1977. Risk, uncertainty, and divergence of opinion. Journal of Finance 32, 1151-1168.

Nagel, S. 2005. Short sales, institutional investors, and the cross-section of stock returns, Journal of Financial Economics 78, 277-309.

Odders-White, E.R. 2000. On the occurrence and consequences of inaccurate trade classification. Journal of Financial Markets 3, 259-286.

Ofek, E., and M. Richardson. 2003. DotCom mania: The rise and fall of internet stock prices. Journal of Finance 58, 1113-1137.

Pastor, L., and R.F. Stambaugh. 2003. Liquidity risk and expected stock returns. Journal of Political Economy 111, 642-685.

Shin, M., B. Zhang, M. Zhong, and D.J. Lee. 2018. Measuring international uncertainty: The case of Korea. Economic Letters 162, 22-26.

Shleifer, A., and R.W. Vishny. 1997. Limits to arbitrage. Journal of Finance 52, 35-55.

Sill, K. 2012. Measuring economic uncertainty using the survey of professional forecasters. Business Review, Federal Reserve Bank of Philadelphia, Fourth Quarter, 16-27.

Stambaugh, R.F., J. Yu, and Y. Yuan. 2012. The short of it: Investor sentiment and anomalies. Journal of Financial Economics 104, 288-302.

Walker, W.E., P. Harremoes, J. Rotmans, J.P. Van der Sluijs, M.B.A. Van Asselt, P. Janssen, and M.P. Krayer von Krauss. 2003. Defining uncertainty: A conceptual basis for uncertainty management in model-based decision support. Integrated Assessment 4, 5-17. 


\section{Figure 1. Returns on uncertainty beta-sorted portfolios}

Panel A (Panel B) shows the risk-adjusted return $\left(\alpha_{5}^{1}\right)$ on portfolios sorted by uncertainty betas (absolute uncertainty betas) and their statistical significance ( $t$-statistics). In each figure, the solid line indicates the risk-adjusted return and the bar indicates the t-statistics of the risk-adjusted return.

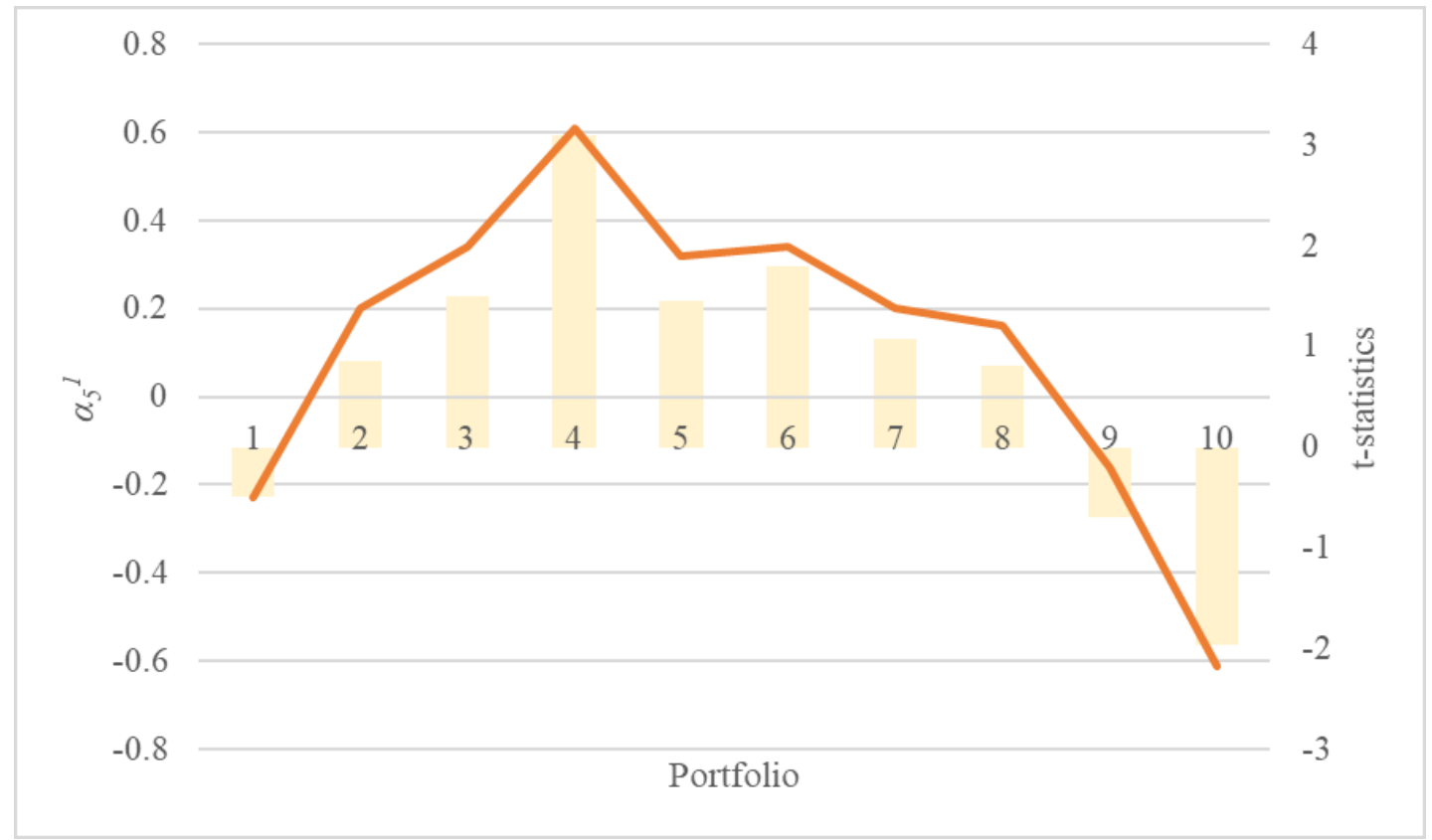

Panel A. Uncertainty beta-sorted portfolios

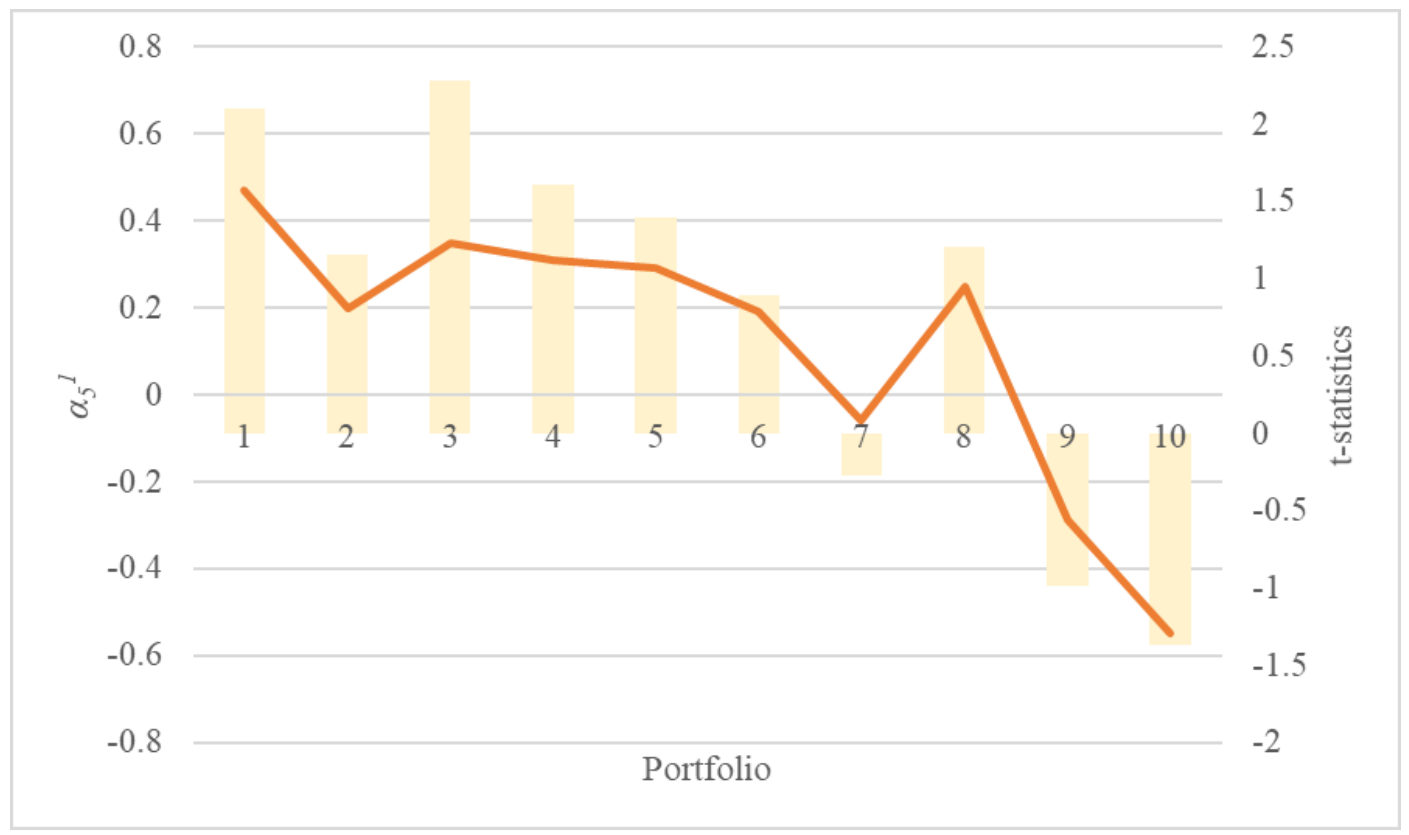

Panel B. Absolute uncertainty beta-sorted portfolios 


\section{Table 1. Uncertainty beta-sorted portfolios}

This table shows the returns on portfolios sorted by the uncertainty beta. For each month, decile portfolios are formed by sorting individual stocks by their uncertainty betas $\left(\beta^{U N C}\right.$ ). Decile 1 (denoted Low) contains stocks with the lowest $\beta^{U N C}$ values and decile 10 (denoted High) contains stocks with the highest. The first column reports the average uncertainty beta of individual stocks in each decile and the remaining columns show the average excess returns (RET-RF) and risk-adjusted returns $\left(\alpha_{5}^{1}, \alpha_{5}^{2}, \alpha_{4}\right.$, and $\left.\alpha_{7}\right)$ for the equal- and value-weighted portfolios separately. We employ a five-factor model including market, size, value, momentum, and liquidity factors; Fama and French's (2015) five-factor model; a fourfactor model including market, size, profitability, and investment factors; and a seven-factor model including market, size, value, momentum, profitability, investment, and liquidity factors. The resulting alphas are denoted $\alpha_{5}^{1}, \alpha_{5}^{2}, \alpha_{4}$, and $\alpha_{7}$, respectively. Newey-West adjusted $t$ statistics are in parentheses. The sample period is from January 1992 to June 2017.

\begin{tabular}{|c|c|c|c|c|c|c|c|c|c|c|c|}
\hline \multirow[b]{2}{*}{ Decile } & \multirow[b]{2}{*}{$\beta^{U N C}$} & \multicolumn{5}{|c|}{ Equal weighted } & \multicolumn{5}{|c|}{ Value weighted } \\
\hline & & RET-RF & $\alpha_{5}^{1}$ & $\alpha_{5}^{2}$ & $\alpha_{4}$ & $\alpha_{7}$ & RET-RF & $\alpha_{5}^{1}$ & $\alpha_{5}^{2}$ & $\alpha_{4}$ & $\alpha_{7}$ \\
\hline \multirow[t]{2}{*}{ Low } & -0.95 & 0.79 & -0.23 & 0.92 & 1.12 & 0.32 & 0.51 & -0.26 & 0.40 & 0.35 & 0.36 \\
\hline & & $(0.88)$ & $(-0.50)$ & $(1.68)$ & $(1.50)$ & $(0.97)$ & $(0.72)$ & $(-0.59)$ & $(0.94)$ & $(0.92)$ & $(0.86)$ \\
\hline \multirow[t]{2}{*}{2} & -0.47 & 1.26 & 0.20 & 0.86 & 1.24 & 0.58 & 0.78 & -0.20 & -0.01 & 0.31 & -0.12 \\
\hline & & (1.79) & $(0.85)$ & $(3.02)$ & $(3.35)$ & $(2.83)$ & $(1.08)$ & $(-0.46)$ & $(-0.03)$ & $(0.96)$ & $(-0.32)$ \\
\hline \multirow[t]{2}{*}{3} & -0.29 & 1.37 & 0.34 & 0.95 & 1.31 & 0.80 & 0.83 & 0.09 & 0.58 & 0.62 & 0.55 \\
\hline & & $(2.16)$ & $(1.49)$ & $(3.85)$ & $(4.73)$ & $(3.90)$ & $(1.17)$ & $(0.26)$ & $(1.49)$ & $(1.78)$ & $(1.44)$ \\
\hline \multirow[t]{2}{*}{4} & -0.16 & 1.64 & 0.61 & 1.02 & 1.42 & 0.83 & 0.92 & 0.09 & 0.12 & 0.50 & 0.13 \\
\hline & & $(2.60)$ & $(3.09)$ & $(4.47)$ & $(5.15)$ & $(4.61)$ & $(1.58)$ & $(0.29)$ & $(0.43)$ & $(1.85)$ & $(0.46)$ \\
\hline \multirow[t]{2}{*}{5} & -0.05 & 1.36 & 0.32 & 0.83 & 1.24 & 0.71 & 0.90 & 0.17 & 0.29 & 0.53 & 0.24 \\
\hline & & $(2.24)$ & $(1.45)$ & $(3.91)$ & $(4.91)$ & (3.9) & $(1.55)$ & $(0.52)$ & $(0.89)$ & $(1.75)$ & $(0.75)$ \\
\hline \multirow[t]{2}{*}{6} & 0.05 & 1.40 & 0.34 & 0.74 & 1.15 & 0.62 & 0.19 & -0.64 & -0.32 & -0.08 & -0.38 \\
\hline & & $(2.30)$ & (1.79) & $(3.50)$ & $(4.57)$ & $(3.46)$ & $(0.29)$ & $(-2.22)$ & $(-1.11)$ & $(-0.30)$ & $(-1.35)$ \\
\hline \multirow[t]{2}{*}{7} & 0.17 & 1.24 & 0.20 & 0.54 & 1.00 & 0.44 & 0.89 & 0.15 & 0.22 & 0.39 & 0.27 \\
\hline & & $(2.06)$ & (1.07) & $(2.64)$ & $(4.22)$ & $(2.52)$ & (1.48) & $(0.48)$ & $(0.76)$ & $(1.37)$ & $(0.97)$ \\
\hline \multirow[t]{2}{*}{8} & 0.30 & 1.21 & 0.16 & 0.58 & 0.98 & 0.46 & 0.63 & -0.09 & 0.13 & 0.35 & 0.04 \\
\hline & & $(1.90)$ & $(0.81)$ & $(2.79)$ & $(4.12)$ & $(2.48)$ & $(1.05)$ & $(-0.33)$ & $(0.40)$ & (1.17) & $(0.13)$ \\
\hline
\end{tabular}




\begin{tabular}{lcccccccccccc}
9 & 0.49 & 0.88 & -0.16 & 0.30 & 0.73 & 0.21 & 1.12 & 0.56 & 0.32 & 0.27 & 0.36 & $(12$ \\
& & $(1.43)$ & $(-0.69)$ & $(1.21)$ & $(2.73)$ & $(0.88)$ & $(1.64)$ & $(1.43)$ & $(0.84)$ & $(0.83)$ & $(0.91)$ \\
High & \multirow{2}{*}{1.03} & 0.45 & -0.61 & 0.05 & 0.38 & -0.11 & 0.26 & -0.69 & -0.52 & -0.27 & -0.52 & $(-11$ \\
& & $(0.64)$ & $(-1.97)$ & $(0.14)$ & $(1.08)$ & $(-0.35)$ & $(0.34)$ & $(-1.69)$ & $(-1.27)$ & $(-0.69)$ & $(-1.32)$ \\
\hline High - Low & & -0.34 & -0.38 & -0.87 & -0.74 & -0.42 & -0.25 & -0.42 & -0.92 & -0.61 & -0.88 \\
& & $(-0.30)$ & $(-0.68)$ & $(-1.36)$ & $(-0.90)$ & $(-0.95)$ & $(-0.24)$ & $(-0.70)$ & $(-1.56)$ & $(-1.14)$ & $(-1.53)$ \\
\hline
\end{tabular}




\section{Table 2. Absolute uncertainty beta-sorted portfolios}

This table shows the returns on portfolios sorted by absolute uncertainty betas $\left(\left|\beta^{U N C}\right|\right)$. For each month, decile portfolios are formed by sorting individual stocks by their absolute uncertainty betas. Decile 1 (denoted Low) contains stocks with the lowest $\left|\beta^{U N C}\right|$ values and decile 10 (denoted High) contains stocks with the highest. The first column reports the average absolute uncertainty beta of individual stocks in each decile and the remaining columns show the average excess returns (RET-RF) and risk-adjusted returns $\left(\alpha_{5}^{1}, \alpha_{5}^{2}, \alpha_{4}\right.$, and $\left.\alpha_{7}\right)$ for the equal- and value-weighted portfolios separately. We employ a five-factor model including market, size, value, momentum, and liquidity factors; Fama and French's (2015) five-factor model; a four-factor model including market, size, profitability, and investment factors; and a seven-factor model including market, size, value, momentum, profitability, investment, and liquidity factors. The resulting alphas are denoted $\alpha_{5}^{1}, \alpha_{5}^{2}, \alpha_{4}$, and $\alpha_{7}$, respectively. Newey-West adjusted $t$-statistics are in parentheses. The sample period is from January 1992 to June 2017.

\begin{tabular}{|c|c|c|c|c|c|c|c|c|c|c|c|}
\hline \multirow[b]{2}{*}{ Decile } & \multirow[b]{2}{*}{$\left|\beta^{U N C}\right|$} & \multicolumn{5}{|c|}{ Equal weighted } & \multicolumn{5}{|c|}{ Value weighted } \\
\hline & & RET-RF & $\alpha_{5}^{1}$ & $\alpha_{5}^{2}$ & $\alpha_{4}$ & $\alpha_{7}$ & RET-RF & $\alpha_{5}^{1}$ & $\alpha_{5}^{2}$ & $\alpha_{4}$ & $\alpha_{7}$ \\
\hline \multirow[t]{2}{*}{ Low } & 0.03 & 1.57 & 0.47 & 0.95 & 1.39 & 0.80 & 0.79 & -0.07 & 0.11 & 0.43 & 0.12 \\
\hline & & $(2.47)$ & $(2.10)$ & $(4.05)$ & $(4.97)$ & $(4.05)$ & $(1.25)$ & $(-0.21)$ & $(0.33)$ & $(1.32)$ & $(0.38)$ \\
\hline \multirow[t]{2}{*}{2} & 0.08 & 1.20 & 0.20 & 0.52 & 0.93 & 0.45 & 0.20 & -0.36 & -0.20 & -0.25 & -0.21 \\
\hline & & $(2.08)$ & $(1.16)$ & $(2.73)$ & $(4.31)$ & $(2.69)$ & $(0.34)$ & $(-1.1)$ & $(-0.66)$ & $(-0.88)$ & $(-0.68)$ \\
\hline \multirow[t]{2}{*}{3} & 0.13 & 1.38 & 0.35 & 0.73 & 1.14 & 0.61 & 0.67 & -0.08 & -0.07 & 0.22 & -0.06 \\
\hline & & $(2.32)$ & $(2.28)$ & $(4.18)$ & $(5.22)$ & $(4.24)$ & (1.17) & $(-0.28)$ & $(-0.27)$ & $(0.86)$ & $(-0.23)$ \\
\hline \multirow[t]{2}{*}{4} & 0.19 & 1.34 & 0.31 & 0.70 & 1.10 & 0.57 & 0.71 & -0.19 & -0.12 & 0.30 & -0.21 \\
\hline & & $(2.18)$ & $(1.61)$ & $(3.19)$ & $(4.36)$ & $(3.07)$ & (1.19) & $(-0.69)$ & $(-0.45)$ & $(1.05)$ & $(-0.77)$ \\
\hline \multirow[t]{2}{*}{5} & 0.26 & 1.39 & 0.29 & 0.83 & 1.27 & 0.65 & 0.86 & -0.08 & 0.22 & 0.63 & 0.19 \\
\hline & & (2.14) & (1.4) & $(3.65)$ & $(4.63)$ & $(3.66)$ & $(1.38)$ & $(-0.25)$ & $(0.77)$ & $(2.32)$ & $(0.69)$ \\
\hline \multirow[t]{2}{*}{6} & 0.33 & 1.25 & 0.19 & 0.66 & 1.06 & 0.57 & 0.89 & 0.30 & 0.44 & 0.33 & 0.48 \\
\hline & & (1.99) & $(0.89)$ & $(2.96)$ & $(4.24)$ & $(2.70)$ & $(1.27)$ & $(0.84)$ & $(1.29)$ & $(1.13)$ & $(1.39)$ \\
\hline \multirow[t]{2}{*}{7} & 0.42 & 0.95 & -0.06 & 0.54 & 0.89 & 0.33 & 0.49 & -0.25 & 0.05 & 0.22 & -0.04 \\
\hline & & $(1.46)$ & $(-0.27)$ & $(2.26)$ & $(2.89)$ & $(1.83)$ & $(0.81)$ & $(-0.87)$ & $(0.13)$ & $(0.68)$ & $(-0.12)$ \\
\hline \multirow[t]{2}{*}{8} & 0.54 & 1.30 & 0.25 & 0.83 & 1.22 & 0.65 & 1.56 & 0.82 & 0.75 & 0.80 & 0.68 \\
\hline & & (1.97) & $(1.21)$ & $(3.74)$ & $(4.51)$ & $(3.72)$ & $(2.18)$ & $(2.31)$ & $(2.03)$ & $(2.64)$ & $(1.95)$ \\
\hline
\end{tabular}




\begin{tabular}{lcccccccccccc}
9 & 0.73 & 0.74 & -0.29 & 0.50 & 0.84 & 0.14 & 0.81 & -0.34 & -0.15 & 0.35 & -0.19 \\
& & $(1.02)$ & $(-0.99)$ & $(1.44)$ & $(1.81)$ & $(0.63)$ & $(1.11)$ & $(-0.96)$ & $(-0.42)$ & $(0.98)$ & $(-0.55)$ \\
High & \multirow{2}{*}{1.26} & 0.48 & -0.55 & 0.51 & 0.72 & 0.08 & -0.64 & -1.46 & -1.03 & -1.01 & -0.99 & $(-0.5)$ \\
& & $(0.58)$ & $(-1.37)$ & $(1.14)$ & $(1.25)$ & $(0.28)$ & $(-0.87)$ & $(-3.62)$ & $(-2.5)$ & $(-2.55)$ & $(-2.48)$ \\
\hline High - Low & & -1.09 & -1.03 & -0.44 & -0.67 & -0.72 & -1.44 & -1.40 & -1.14 & -1.44 & -1.12 \\
& & $(-1.05)$ & $(-2.22)$ & $(-0.86)$ & $(-1.06)$ & $(-2.1)$ & $(-1.47)$ & $(-2.72)$ & $(-2.18)$ & $(-2.81)$ & $(-2.18)$ \\
\hline
\end{tabular}




\section{Table 3. Stock characteristics and the uncertainty beta}

Panel A shows the average stock characteristics of portfolios sorted by $\beta^{U N C}$. Decile 1 (denoted Low) contains stocks with the lowest $\beta^{U N C}$ values and decile 10 (denoted High) contains stocks with the highest. For stock characteristics, this table reports the market beta $\left(\beta^{M K T}\right)$, market capitalization (SIZE), the book-to-market ratio (BM), momentum (MOM), short-term reversal (REV), illiquidity (LIQ), coskewness (COSKEW), idiosyncratic volatility (IVOL), the annual growth of book assets (I/A), annual operating profitability (ROE), and lottery demand (MAX). Panel B presents the Fama-MacBeth regressions of $\left|\beta^{U N C}\right|$ on firm characteristics. From models (1) to (10), we run a univariate regression including each of the characteristics separately and model (11) presents the multivariate regression results. Newey-West adjusted $t$-statistics are in parentheses. The sample period is from January 1992 to June 2017.

\begin{tabular}{|c|c|c|c|c|c|c|c|c|c|c|}
\hline \multicolumn{11}{|c|}{ Panel A: Average stock characteristics of $\beta^{U N C}$-sorted portfolios } \\
\hline Decile & $\beta^{M K T}$ & SIZE & $\mathrm{BM}$ & MOM & REV & ILLIQ & COSKEW & $\mathrm{I} / \mathrm{A}$ & ROE & MAX \\
\hline Low & 0.972 & 10.948 & -0.109 & 0.222 & 0.011 & 0.017 & -0.083 & 0.186 & 0.233 & 0.050 \\
\hline 2 & 0.960 & 11.206 & 0.157 & 0.178 & 0.007 & 0.010 & -0.064 & 0.148 & -0.051 & 0.044 \\
\hline 3 & 0.925 & 11.357 & 0.234 & 0.151 & 0.011 & 0.007 & -0.057 & 0.147 & -0.038 & 0.041 \\
\hline 4 & 0.922 & 11.446 & 0.275 & 0.153 & 0.012 & 0.005 & -0.040 & 0.134 & 0.021 & 0.040 \\
\hline 5 & 0.915 & 11.461 & 0.296 & 0.147 & 0.013 & 0.005 & -0.033 & 0.123 & -0.011 & 0.039 \\
\hline 6 & 0.935 & 11.453 & 0.290 & 0.158 & 0.013 & 0.007 & -0.023 & 0.116 & -0.073 & 0.039 \\
\hline 7 & 0.959 & 11.468 & 0.256 & 0.175 & 0.016 & 0.005 & -0.012 & 0.127 & -0.053 & 0.040 \\
\hline 8 & 0.978 & 11.413 & 0.211 & 0.188 & 0.017 & 0.005 & 0.002 & 0.131 & -0.114 & 0.041 \\
\hline 9 & 1.011 & 11.294 & 0.126 & 0.225 & 0.022 & 0.007 & 0.020 & 0.139 & -0.071 & 0.043 \\
\hline High & 1.063 & 11.136 & -0.083 & 0.342 & 0.037 & 0.010 & 0.046 & 0.188 & -0.894 & 0.048 \\
\hline \multicolumn{11}{|c|}{ Panel B: Cross-sectional regression on stock characteristics } \\
\hline Variable & (1) & (2) & (3) & (4) & $(5)$ & (6) & (8) & (9) & $(10)$ & (11) \\
\hline \multirow[t]{2}{*}{$\beta^{M K T}$} & 0.057 & & & & & & & & & 0.050 \\
\hline & $(3.84)$ & & & & & & & & & $(3.20)$ \\
\hline \multirow[t]{2}{*}{ SIZE } & & -0.030 & & & & & & & & -0.035 \\
\hline & & $(-5.80)$ & & & & & & & & $(-6.14)$ \\
\hline $\mathrm{BM}$ & & & -0.093 & & & & & & & -0.098 \\
\hline
\end{tabular}




\begin{tabular}{|c|c|c|c|c|c|c|c|c|}
\hline & $(-7.24)$ & & & & & & & $(-7.69)$ \\
\hline \multirow[t]{2}{*}{ MOM } & 0.011 & & & & & & & 0.052 \\
\hline & $(0.58)$ & & & & & & & $(4.10)$ \\
\hline \multirow[t]{2}{*}{ REV } & & 0.008 & & & & & & 0.053 \\
\hline & & $(0.46)$ & & & & & & (3.36) \\
\hline \multirow[t]{2}{*}{ ILLIQ } & & & -12.534 & & & & & -7.229 \\
\hline & & & $(-1.63)$ & & & & & $(-1.80)$ \\
\hline \multirow[t]{2}{*}{ COSKEW } & & & & 0.016 & & & & 0.028 \\
\hline & & & & $(0.74)$ & & & & $(1.37)$ \\
\hline \multirow[t]{2}{*}{$\mathrm{I} / \mathrm{A}$} & & & & & 0.017 & & & 0.040 \\
\hline & & & & & (1.44) & & & (4.69) \\
\hline \multirow[t]{2}{*}{ ROE } & & & & & & -0.028 & & -0.014 \\
\hline & & & & & & $(-3.21)$ & & $(-3.13)$ \\
\hline \multirow[t]{2}{*}{ MAX } & & & & & & & 2.365 & 1.382 \\
\hline & & & & & & & (9.54) & (7.63) \\
\hline
\end{tabular}




\section{Table 4. Fama-MacBeth cross-sectional regressions}

This table shows the time-series averages of the slope coefficients obtained from regressing monthly excess returns on the absolute uncertainty beta $\left(\left|\beta^{U N C}\right|\right)$ and a set of predictive variables using the (value-weighted) Fama-MacBeth methodology. Newey-West adjusted $t$-statistics are in parentheses. The sample period is from January 1992 to June 2017.

\begin{tabular}{cccccc}
\hline Variable & $(1)$ & $(2)$ & $(3)$ & $(4)$ & $(5)$ \\
\hline$\left|\beta^{U N C}\right|$ & -0.011 & -0.010 & -0.009 & -0.008 & -0.005 \\
& $(-3.43)$ & $(-3.35)$ & $(-3.48)$ & $(-3.26)$ & $(-1.81)$ \\
$\beta^{M K T}$ & & -0.001 & 0.002 & 0.003 & 0.004 \\
& & $(-0.20)$ & $(0.73)$ & $(0.84)$ & $(1.41)$ \\
SIZE & & -0.002 & -0.002 & -0.004 \\
& & $(-1.97)$ & $(-2.01)$ & $(-3.26)$ \\
BM & & 0.006 & 0.007 & 0.005 \\
& & $(4.01)$ & $(4.35)$ & $(3.51)$ \\
MOM & & -0.003 & -0.002 & -0.001 \\
& & $(-0.91)$ & $(-0.86)$ & $(-0.49)$ \\
REV & & & -0.013 & -0.010 \\
& & & $(-2.43)$ & $(-1.78)$ \\
ILLIQ & & & -0.209 & -0.311 \\
COSKEW & & & $(-0.42)$ & $(-0.50)$ \\
I/A & & & 0.000 & -0.001 \\
ROE & & & $(0.04)$ & $(-0.21)$ \\
MAX & & & -0.003 & -0.004 \\
& & & $-2.40)$ & $(-2.46)$ \\
& & & 0.002 & 0.001 \\
& & & $(2.31)$ & $(1.56)$ \\
& & & & -0.429 \\
& & & & $-6.87)$ \\
\hline
\end{tabular}




\section{Table 5. Long-term Fama-MacBeth cross-sectional regressions}

This table shows the time-series averages of the slope coefficients obtained from regressing monthly excess returns two to 12 months ahead against the absolute uncertainty beta $\left(\left|\beta^{U N C}\right|\right)$ on $\left|\beta^{U N C}\right|$ and a set of predictive variables using the (value-weighted) Fama-MacBeth methodology. Newey-West adjusted $t$-statistics are in parentheses. The sample period is from January 1992 to June 2017.

\begin{tabular}{|c|c|c|c|c|c|c|c|c|c|c|c|}
\hline Variable & $n=2$ & $n=3$ & $n=4$ & $n=5$ & $n=6$ & $n=7$ & $n=8$ & $n=9$ & $n=10$ & $n=11$ & $n=12$ \\
\hline \multirow[t]{2}{*}{$\left|\beta^{U N C}\right|$} & -0.006 & -0.007 & -0.007 & 0.03 & 0.039 & 0.013 & 0.027 & -0.005 & -0.005 & -0.005 & -0.006 \\
\hline & $(-3.01)$ & $(-3.54)$ & $(-3.70)$ & $(0.85)$ & $(0.88)$ & $(0.72)$ & $(0.86)$ & $(-2.12)$ & $(-2.25)$ & $(-2.72)$ & $(-3.25)$ \\
\hline \multirow[t]{2}{*}{$\beta^{M K T}$} & -0.000 & -0.001 & -0.002 & 0.006 & 0.001 & 0.003 & 0.011 & 0.011 & -0.002 & 0.002 & 0.006 \\
\hline & $(-0.09)$ & $(-0.47)$ & $(-0.58)$ & $(0.96)$ & $(0.27)$ & $(0.63)$ & $(1.10)$ & $(0.90)$ & $(-0.76)$ & $(0.56)$ & $(0.99)$ \\
\hline \multirow[t]{2}{*}{ SIZE } & -0.003 & -0.002 & -0.001 & -0.01 & -0.009 & -0.008 & -0.006 & -0.001 & -0.001 & -0.001 & -0.002 \\
\hline & $(-2.44)$ & $(-1.77)$ & $(-1.02)$ & $(-1.16)$ & $(-1.14)$ & $(-1.20)$ & $(-1.23)$ & $(-1.04)$ & $(-0.73)$ & $(-1.29)$ & $(-1.93)$ \\
\hline \multirow[t]{2}{*}{$\mathrm{BM}$} & 0.006 & 0.006 & 0.006 & -0.021 & -0.024 & -0.022 & -0.019 & 0.006 & 0.005 & 0.005 & 0.005 \\
\hline & $(4.04)$ & $(4.15)$ & $(4.18)$ & $(-0.81)$ & $(-0.84)$ & $(-0.85)$ & $(-0.81)$ & $(3.35)$ & $(3.45)$ & $(3.10)$ & (3.24) \\
\hline \multirow[t]{2}{*}{ MOM } & -0.001 & -0.001 & -0.002 & -0.011 & -0.016 & -0.023 & -0.031 & -0.004 & -0.006 & -0.004 & -0.003 \\
\hline & $(-0.29)$ & $(-0.48)$ & $(-0.66)$ & $(-1.39)$ & $(-1.24)$ & $(-1.21)$ & $(-1.23)$ & $(-1.94)$ & $(-1.99)$ & $(-3.18)$ & $(-1.99)$ \\
\hline \multirow[t]{2}{*}{ REV } & -0.002 & 0.004 & 0.002 & -0.159 & 0.035 & -0.023 & -0.134 & -0.012 & 0.006 & 0.007 & 0.005 \\
\hline & $(-0.38)$ & $(0.84)$ & $(0.37)$ & $(-1.02)$ & $(1.05)$ & $(-0.74)$ & $(-0.96)$ & $(-0.58)$ & $(1.57)$ & $(1.08)$ & $(0.41)$ \\
\hline \multirow[t]{2}{*}{ ILLIQ } & 0.288 & 0.127 & 0.241 & 0.360 & -0.664 & -0.713 & 0.572 & 0.350 & 0.517 & 0.580 & 0.545 \\
\hline & $(1.10)$ & $(0.47)$ & $(0.75)$ & $(0.41)$ & $(-1.04)$ & $(-0.91)$ & $(1.25)$ & $(1.41)$ & $(1.75)$ & $(1.31)$ & $(1.92)$ \\
\hline \multirow[t]{2}{*}{ COSKEW } & 0.000 & 0.001 & -0.003 & -0.025 & -0.026 & -0.031 & -0.034 & 0.005 & -0.001 & 0.002 & -0.003 \\
\hline & $(-0.02)$ & $(0.46)$ & $(-0.93)$ & $(-1.08)$ & $(-1.18)$ & $(-1.07)$ & $(-1.03)$ & (1.33) & $(-0.49)$ & $(1.12)$ & $(-0.56)$ \\
\hline \multirow[t]{2}{*}{$\mathrm{I} / \mathrm{A}$} & -0.004 & -0.003 & -0.003 & -0.092 & -0.101 & -0.101 & -0.106 & -0.002 & -0.002 & -0.001 & 0.0002 \\
\hline & $(-2.17)$ & $(-2.18)$ & $(-2.03)$ & $(-1.07)$ & $(-1.07)$ & $(-1.06)$ & $(-1.05)$ & $(-1.65)$ & $(-1.42)$ & $(-0.82)$ & $(0.21)$ \\
\hline \multirow[t]{2}{*}{$\mathrm{ROE}$} & 0.002 & 0.002 & 0.002 & 0.025 & 0.022 & 0.019 & 0.018 & 0.002 & 0.002 & 0.002 & 0.002 \\
\hline & $(2.67)$ & $(1.78)$ & $(2.12)$ & $(1.09)$ & $(1.13)$ & $(1.17)$ & $(1.15)$ & $(3.31)$ & $(3.27)$ & $(3.06)$ & (3.09) \\
\hline \multirow[t]{2}{*}{ MAX } & -0.259 & -0.205 & -0.141 & -0.296 & -0.867 & -0.581 & -0.648 & -0.134 & -0.231 & -0.130 & -0.074 \\
\hline & $(-6.33)$ & $(-5.70)$ & $(-3.44)$ & $(-1.62)$ & $(-1.17)$ & $(-1.31)$ & $(-1.29)$ & $(-4.88)$ & $(-1.84)$ & $(-3.95)$ & $(-1.61)$ \\
\hline
\end{tabular}




\section{Table 6. Double-sorted portfolios}

This table presents the returns on two-way independently sorted portfolios. For each stock in each month, the RTP is computed by the total retail trading volume (sum of buy- and sell-initiated trades by retail investors) divided by the total trading volume, following Brandt et al. (2009). We sort sample stocks by RTP into three groups and independently sort stocks by $\left|\beta^{U N C}\right|$ into 10 groups. The value-weighted returns on each portfolio and the long-short portfolios - high RTP - low RTP portfolio (denoted 3-1) and high $\left|\beta^{U N C}\right|$ - low $\left|\beta^{U N C}\right|$ portfolio (denoted High-Low)-are computed and the average excess returns (RET-RF) and risk-adjusted returns $\left(\alpha_{5}^{1}, \alpha_{5}^{2}, \alpha_{4}\right.$, and $\left.\alpha_{7}\right)$ are reported. Newey-West adjusted $t$-statistics are in parentheses. The sample period is from January 2006 to November 2014.

\begin{tabular}{|c|c|c|c|c|c|c|c|c|c|c|c|c|c|c|c|c|c|c|c|c|}
\hline \multirow[b]{2}{*}{ Decile } & \multicolumn{4}{|c|}{ RET-RF } & \multicolumn{4}{|c|}{$\alpha_{5}^{1}$} & \multicolumn{4}{|c|}{$\alpha_{5}^{2}$} & \multicolumn{4}{|c|}{$\alpha_{4}$} & \multicolumn{4}{|c|}{$\alpha_{7}$} \\
\hline & RTP1 & 2 & RTP3 & $3-1$ & RTP1 & 2 & RTP3 & $3-1$ & RTP1 & 2 & RTP3 & $3-1$ & RTP1 & 2 & RTP3 & 3-1 & RTP1 & 2 & RTP3 & $3-1$ \\
\hline \multirow{2}{*}{$\begin{array}{l}\text { Low } \\
\left|\beta^{U N C}\right|\end{array}$} & 0.62 & 0.31 & -0.10 & -0.72 & 0.50 & -0.22 & -0.31 & -0.82 & 0.53 & -0.17 & -0.21 & -0.74 & 0.41 & 0.06 & -0.11 & -0.52 & 0.51 & -0.17 & -0.18 & -0.69 \\
\hline & $(1.21)$ & $(0.41)$ & $(-0.14)$ & $(-0.83)$ & $(1.50)$ & $(-0.6)$ & $(-0.80)$ & $(-1.58)$ & $(1.50)$ & $(-0.44)$ & $(-0.54)$ & $(-1.40)$ & $(1.30)$ & $(0.15)$ & $(-0.30)$ & $(-1.06)$ & $(1.47)$ & $(-0.46)$ & $(-0.46)$ & $(-1.32)$ \\
\hline \multirow[t]{2}{*}{2} & 0.44 & 0.93 & -0.30 & -0.74 & 0.42 & 0.15 & -0.62 & -1.04 & 0.35 & 0.38 & -0.54 & -0.88 & 0.14 & 0.81 & -0.42 & -0.55 & 0.35 & 0.34 & -0.53 & -0.89 \\
\hline & $(0.74)$ & $(1.14)$ & $(-0.42)$ & $(-0.8)$ & $(1.15)$ & $(0.32)$ & $(-1.83)$ & $(-2.08)$ & $(0.92)$ & $(0.78)$ & $(-1.57)$ & $(-1.74)$ & $(0.38)$ & $(1.78)$ & $(-1.28)$ & $(-1.15)$ & $(0.94)$ & $(0.70)$ & $(-1.53)$ & $(-1.73)$ \\
\hline \multirow[t]{2}{*}{3} & 0.49 & 0.50 & 0.06 & -0.43 & 0.27 & -0.15 & -0.53 & -0.80 & 0.17 & -0.11 & -0.45 & -0.61 & 0.17 & 0.16 & -0.14 & -0.31 & 0.19 & -0.15 & -0.46 & -0.66 \\
\hline & $(0.84)$ & $(0.65)$ & $(0.08)$ & $(-0.45)$ & $(0.88)$ & $(-0.45)$ & $(-1.16)$ & $(-1.46)$ & $(0.53)$ & $(-0.34)$ & $(-0.97)$ & $(-1.10)$ & $(0.58)$ & $(0.48)$ & $(-0.31)$ & $(-0.57)$ & $(0.62)$ & $(-0.45)$ & $(-0.98)$ & $(-1.15)$ \\
\hline \multirow[t]{2}{*}{4} & 0.36 & 0.51 & -0.14 & -0.50 & -0.14 & -0.14 & -0.37 & -0.23 & -0.14 & 0.05 & -0.15 & 0.00 & 0.07 & 0.39 & -0.09 & -0.16 & -0.15 & 0.03 & -0.14 & 0.01 \\
\hline & $(0.59)$ & $(0.63)$ & $(-0.19)$ & $(-0.51)$ & $(-0.42)$ & $(-0.31)$ & $(-0.97)$ & $(-0.46)$ & $(-0.44)$ & $(0.10)$ & $(-0.43)$ & $(0.00)$ & $(0.23)$ & $(0.92)$ & $(-0.28)$ & $(-0.36)$ & $(-0.46)$ & $(0.06)$ & $(-0.41)$ & $(0.03)$ \\
\hline \multirow[t]{2}{*}{5} & 0.48 & 0.59 & 0.21 & -0.27 & 0.18 & 0.28 & -0.33 & -0.50 & 0.10 & 0.45 & -0.42 & -0.52 & 0.21 & 0.58 & -0.09 & -0.30 & 0.14 & 0.49 & -0.41 & -0.55 \\
\hline & $(0.76)$ & $(0.73)$ & $(0.29)$ & $(-0.28)$ & $(0.57)$ & $(0.61)$ & $(-0.82)$ & $(-1.00)$ & $(0.31)$ & $(0.99)$ & $(-1.04)$ & $(-1.01)$ & $(0.67)$ & $(1.36)$ & $(-0.25)$ & $(-0.63)$ & $(0.43)$ & $(1.05)$ & $(-1.00)$ & $(-1.05)$ \\
\hline \multirow[t]{2}{*}{6} & -0.18 & 0.59 & -0.45 & -0.26 & -0.83 & -0.62 & -0.89 & -0.06 & -0.69 & -0.42 & -0.78 & -0.09 & -0.35 & 0.38 & -0.55 & -0.20 & -0.71 & -0.48 & -0.77 & -0.07 \\
\hline & $(-0.26)$ & $(0.70)$ & $(-0.59)$ & $(-0.26)$ & $(-2.45)$ & $(-1.85)$ & $(-2.44)$ & $(-0.12)$ & $(-1.94)$ & $(-1.19)$ & $(-2.11)$ & $(-0.17)$ & $(-1.01)$ & $(0.78)$ & $(-1.49)$ & $(-0.39)$ & $(-2.01)$ & $(-1.39)$ & $(-2.10)$ & $(-0.13)$ \\
\hline \multirow[t]{2}{*}{7} & 0.48 & 0.05 & -0.16 & -0.64 & 0.05 & -0.50 & -0.81 & -0.85 & 0.15 & -0.40 & -0.71 & -0.86 & 0.36 & -0.13 & -0.30 & -0.66 & 0.17 & -0.39 & -0.71 & -0.89 \\
\hline & $(0.68)$ & $(0.06)$ & $(-0.19)$ & $(-0.59)$ & $(0.11)$ & $(-0.85)$ & $(-2.09)$ & $(-1.49)$ & $(0.34)$ & $(-0.63)$ & $(-1.79)$ & $(-1.44)$ & $(0.91)$ & $(-0.22)$ & $(-0.74)$ & $(-1.17)$ & $(0.40)$ & $(-0.62)$ & $(-1.81)$ & $(-1.50)$ \\
\hline \multirow[t]{2}{*}{8} & 1.12 & 0.21 & -1.11 & -2.23 & 0.23 & -0.24 & -1.29 & -1.51 & 0.33 & -0.28 & -1.22 & -1.55 & 0.79 & -0.02 & -1.23 & -2.01 & 0.29 & -0.24 & -1.21 & -1.50 \\
\hline & $(1.32)$ & $(0.24)$ & $(-1.48)$ & $(-1.97)$ & $(0.47)$ & $(-0.50)$ & $(-3.78)$ & $(-2.56)$ & $(0.66)$ & $(-0.56)$ & $(-3.68)$ & $(-2.59)$ & $(1.64)$ & $(-0.05)$ & $(-3.75)$ & $(-3.47)$ & $(0.57)$ & $(-0.49)$ & $(-3.63)$ & $(-2.48)$ \\
\hline \multirow[t]{2}{*}{9} & 0.30 & 0.97 & -1.30 & -1.61 & -0.50 & 0.49 & -1.68 & -1.18 & -0.26 & 0.74 & -1.67 & -1.40 & 0.09 & 0.96 & -1.53 & -1.62 & -0.32 & 0.73 & -1.67 & -1.35 \\
\hline & $(0.33)$ & $(1.24)$ & $(-1.55)$ & $(-1.29)$ & $(-0.92)$ & $(0.99)$ & $(-3.64)$ & $(-1.65)$ & $(-0.48)$ & $(1.40)$ & $(-3.67)$ & $(-1.97)$ & $(0.16)$ & $(1.82)$ & $(-3.28)$ & $(-2.24)$ & $(-0.57)$ & $(1.37)$ & $(-3.62)$ & $(-1.87)$ \\
\hline \multirow{2}{*}{$\begin{array}{l}\text { High } \\
\left|\beta^{U N C}\right|\end{array}$} & 0.69 & -0.12 & -1.99 & -2.68 & 0.62 & -0.49 & -2.28 & -2.90 & 0.57 & -0.25 & -2.09 & -2.66 & 0.20 & -0.24 & -1.98 & -2.18 & 0.52 & -0.33 & -2.08 & -2.60 \\
\hline & $(0.57)$ & $(-0.13)$ & $(-2.51)$ & $(-1.86)$ & $(0.47)$ & $(-0.83)$ & $(-5.79)$ & $(-2.12)$ & $(0.39)$ & $(-0.37)$ & $(-5.62)$ & $(-1.77)$ & $(0.17)$ & $(-0.39)$ & $(-5.39)$ & $(-1.73)$ & $(0.35)$ & $(-0.50)$ & $(-5.62)$ & $(-1.72)$ \\
\hline \multirow{2}{*}{$\begin{array}{l}\text { High - } \\
\text { Low }\end{array}$} & -0.05 & -0.17 & -2.07 & & -0.55 & 0.09 & -2.18 & & -0.55 & 0.17 & -1.98 & & -0.24 & -0.10 & -1.94 & & -0.58 & 0.14 & -2.02 & \\
\hline & $(-0.05)$ & $(-0.14)$ & $(-1.91)$ & & $(-0.94)$ & $(0.13)$ & $(-3.77)$ & & $(-0.94)$ & $(0.23)$ & $(-3.54)$ & & $(-0.44)$ & $(-0.15)$ & $(-3.62)$ & & $(-0.97)$ & $(0.19)$ & $(-3.65)$ & \\
\hline
\end{tabular}




\section{Table 7. Fama-MacBeth cross-sectional regressions with retail trading}

This table shows the time-series averages of the slope coefficients obtained from regressing monthly excess returns on the absolute uncertainty beta $\left(\left|\beta^{U N C}\right|\right)$, the interaction between the absolute uncertainty beta and a dummy for high retail trading $\left(\left|\beta^{U N C}\right| \times H\right)$, and a set of predictive variables using the Fama-MacBeth methodology. For each stock in each month, the RTP is computed by the total retail trading volume (sum of buy- and sell-initiated trades by retail investors) divided by the total trading volume, following Brandt et al. (2009). Using the 70th percentile of the RTP of all KOSPI stocks as a standard for high-retail trading firms, the dummy variable $H$ has the value of one if the RTP of the stock is above the standard and zero otherwise. Newey-West adjusted $t$-statistics are in parentheses. The sample period is from January 2006 to November 2014.

\begin{tabular}{|c|c|c|c|c|c|}
\hline Variable & (1) & (2) & (3) & (4) & (5) \\
\hline \multirow[t]{2}{*}{$\left|\beta^{U N C}\right| \times H$} & -0.014 & -0.014 & -0.025 & -0.024 & -0.014 \\
\hline & $(-2.55)$ & $(-2.56)$ & $(-3.90)$ & $(-3.64)$ & $(-2.47)$ \\
\hline \multirow[t]{2}{*}{$\left|\beta^{U N C}\right|$} & -0.007 & -0.005 & 0.000 & 0.000 & 0.000 \\
\hline & $(-1.88)$ & $(-1.50)$ & $(-0.04)$ & $(0.10)$ & $(0.06)$ \\
\hline \multirow[t]{2}{*}{$\beta^{M K T}$} & & -0.004 & -0.003 & -0.002 & -0.001 \\
\hline & & $(-1.73)$ & $(-1.30)$ & $(-0.95)$ & $(-0.34)$ \\
\hline \multirow[t]{2}{*}{ SIZE } & & & -0.003 & -0.003 & -0.004 \\
\hline & & & $(-2.85)$ & $(-2.74)$ & $(-3.34)$ \\
\hline \multirow[t]{2}{*}{$\mathrm{BM}$} & & & 0.006 & 0.007 & 0.005 \\
\hline & & & $(3.35)$ & $(3.39)$ & $(2.27)$ \\
\hline \multirow[t]{2}{*}{ MOM } & & & 0.001 & 0.001 & 0.002 \\
\hline & & & $(0.37)$ & $(0.29)$ & $(0.98)$ \\
\hline \multirow[t]{2}{*}{ REV } & & & & -0.005 & -0.001 \\
\hline & & & & $(-0.86)$ & $(-0.15)$ \\
\hline \multirow[t]{2}{*}{ ILLIQ } & & & & 0.325 & 0.286 \\
\hline & & & & $(1.28)$ & $(1.14)$ \\
\hline \multirow[t]{2}{*}{ COSKEW } & & & & 0.001 & 0.000 \\
\hline & & & & $(0.25)$ & $(-0.08)$ \\
\hline \multirow[t]{2}{*}{$\mathrm{I} / \mathrm{A}$} & & & & -0.003 & -0.003 \\
\hline & & & & $(-2.54)$ & $(-2.46)$ \\
\hline \multirow[t]{2}{*}{ ROE } & & & & 0.002 & 0.001 \\
\hline & & & & $(1.75)$ & $(0.88)$ \\
\hline \multirow[t]{2}{*}{ MAX } & & & & & -0.374 \\
\hline & & & & & $(-6.55)$ \\
\hline
\end{tabular}




\section{Table 8. Long-term Fama-MacBeth cross-sectional regressions with retail trading}

This table shows the time-series averages of the slope coefficients obtained from regressing monthly excess returns two to 12 months ahead against the absolute uncertainty beta $\left(\left|\beta^{U N C}\right|\right)$, the interaction between the absolute uncertainty beta and a dummy for high levels of retail trading $\left(\left|\beta^{U N C}\right| \times H\right)$, and a set of predictive variables using the Fama-MacBeth methodology. Newey-West adjusted $t$-statistics are in parentheses. The sample period is from January 1992 to June 2017.

\begin{tabular}{cccccccccccc}
\hline Variable & $n=2$ & $n=3$ & $n=4$ & $n=5$ & $n=6$ & $n=7$ & $n=8$ & $n=9$ & $n=10$ & $n=11$ & $n=12$ \\
\hline$\left|\beta^{U N C}\right| \times H$ & -0.014 & -0.014 & -0.015 & -0.013 & -0.013 & -0.013 & -0.012 & -0.012 & -0.013 & -0.012 & -0.012 \\
& $(-2.59)$ & $(-2.58)$ & $(-2.58)$ & $(-2.32)$ & $(-2.25)$ & $(-2.16)$ & $(-2.09)$ & $(-2.13)$ & $(-2.17)$ & $(-2.07)$ & $(-2.14)$ \\
$\left|\beta^{U N C}\right|$ & 0.000 & 0.000 & 0.001 & 0.000 & 0.000 & 0.001 & 0.001 & 0.001 & 0.001 & 0.001 & 0.001 \\
& $(0.07)$ & $(0.09)$ & $(0.13)$ & $(0.07)$ & $(0.05)$ & $(0.15)$ & $(0.20)$ & $(0.32)$ & $(0.34)$ & $(0.35)$ & $(0.35)$ \\
\multirow{2}{*}{$\beta^{M K T}$} & -0.001 & -0.001 & -0.001 & -0.001 & -0.001 & -0.001 & -0.001 & -0.001 & -0.001 & -0.001 & -0.001 \\
& $(-0.48)$ & $(-0.41)$ & $(-0.37)$ & $(-0.40)$ & $(-0.49)$ & $(-0.42)$ & $(-0.39)$ & $(-0.43)$ & $(-0.48)$ & $(-0.49)$ & $(-0.47)$ \\
SIZE & -0.003 & -0.003 & -0.003 & -0.003 & -0.003 & -0.003 & -0.003 & -0.003 & -0.003 & -0.003 & -0.003 \\
& $(-2.86)$ & $(-2.88)$ & $(-2.9)$ & $(-2.89)$ & $(-2.91)$ & $(-2.93)$ & $(-2.95)$ & $(-2.96)$ & $(-2.98)$ & $(-3.01)$ & $(-3.03)$ \\
BM & 0.005 & 0.005 & 0.005 & 0.005 & 0.005 & 0.005 & 0.005 & 0.005 & 0.004 & 0.004 & 0.004 \\
& $(2.34)$ & $(2.33)$ & $(2.30)$ & $(2.30)$ & $(2.28)$ & $(2.27)$ & $(2.22)$ & $(2.18)$ & $(2.14)$ & $(2.08)$ & $(2.05)$ \\
MOM & 0.002 & 0.002 & 0.001 & 0.001 & 0.001 & 0.001 & 0.001 & 0.001 & 0.001 & 0.0005 & 0.0004 \\
& $(0.75)$ & $(0.66)$ & $(0.64)$ & $(0.54)$ & $(0.54)$ & $(0.46)$ & $(0.39)$ & $(0.35)$ & $(0.29)$ & $(0.20)$ & $(0.18)$ \\
REV & -0.002 & -0.002 & -0.002 & -0.003 & -0.004 & -0.004 & -0.004 & -0.004 & -0.003 & -0.003 & -0.003 \\
& $(-0.25)$ & $(-0.28)$ & $(-0.32)$ & $(-0.48)$ & $(-0.53)$ & $(-0.56)$ & $(-0.54)$ & $(-0.6)$ & $(-0.52)$ & $(-0.47)$ & $(-0.48)$ \\
ILLIQ & 0.281 & 0.280 & 0.277 & 0.277 & 0.274 & 0.270 & 0.270 & 0.269 & 0.265 & 0.259 & 0.259 \\
& $(1.14)$ & $(1.14)$ & $(1.12)$ & $(1.12)$ & $(1.11)$ & $(1.10)$ & $(1.10)$ & $(1.09)$ & $(1.08)$ & $(1.07)$ & $(1.07)$ \\
COSKEW & 0.000 & -0.001 & 0.000 & 0.000 & 0.000 & 0.000 & 0.000 & 0.000 & 0.000 & 0.000 & 0.000 \\
& $(-0.11)$ & $(-0.13)$ & $(-0.11)$ & $(-0.06)$ & $(0.03)$ & $(0.03)$ & $(0.00)$ & $(0.01)$ & $(0.01)$ & $(-0.02)$ & $(-0.02)$ \\
I/A & -0.002 & -0.002 & -0.002 & -0.002 & -0.002 & -0.002 & -0.002 & -0.002 & -0.002 & -0.002 & -0.002 \\
& $(-2.39)$ & $(-2.37)$ & $(-2.32)$ & $(-2.25)$ & $(-2.29)$ & $(-2.05)$ & $(-2.09)$ & $(-2.09)$ & $(-1.95)$ & $(-1.95)$ & $(-1.98)$ \\
ROE & 0.001 & 0.001 & 0.001 & 0.001 & 0.001 & 0.001 & 0.001 & 0.001 & 0.001 & 0.001 & 0.001 \\
& & & & & & & & & &
\end{tabular}




\begin{tabular}{cccccccccccc} 
& $(1.01)$ & $(0.98)$ & $(1.01)$ & $(1.02)$ & $(1.03)$ & $(0.97)$ & $(0.89)$ & $(0.86)$ & $(0.75)$ & $(0.66)$ & $(0.72)$ \\
\multirow{2}{*}{ MAX } & -0.364 & -0.362 & -0.36 & -0.355 & -0.351 & -0.348 & -0.345 & -0.342 & -0.337 & -0.332 & -0.331 \\
& $(-6.59)$ & $(-6.50)$ & $(-6.49)$ & $(-6.36)$ & $(-6.25)$ & $(-6.13)$ & $(-6.08)$ & $(-6.03)$ & $(-6.01)$ & $(-5.97)$ & $(-5.89)$ \\
\hline
\end{tabular}




\section{Table 9. Double-sorted portfolios in high-sentiment periods}

This table presents the returns on two-way independently sorted portfolios in high-sentiment periods. Based on the residuals of Eq. (4), we define a high-sentiment month as one in which the residual of the previous month is positive. For each stock in each month, the RTP is computed by the total retail trading volume (sum of buy- and sell-initiated trades by retail investors) divided by the total trading volume, following Brandt et al. (2009). We sort sample stocks by the RTP into three groups and independently sort stocks by $\left|\beta^{U N C}\right|$ into 10 groups. The value-weighted returns on each portfolio and the long-short portfolios-high RTP - low RTP portfolio (denoted 3-1) and high $\left|\beta^{U N C}\right|-$ low $\left|\beta^{U N C}\right|$ portfolio (denoted High-Low) - are computed and the average excess returns (RET-RF) and risk-adjusted returns $\left(\alpha_{5}^{1}, \alpha_{5}^{2}, \alpha_{4}\right.$, and $\left.\alpha_{7}\right)$ are reported. Newey-West adjusted $t$-statistics are in parentheses. The total sample period is from January 2006 to November 2014.

\begin{tabular}{|c|c|c|c|c|c|c|c|c|c|c|c|c|c|c|c|c|c|c|c|c|}
\hline \multirow[b]{2}{*}{ Decile } & \multicolumn{4}{|c|}{ RET-RF } & \multicolumn{4}{|c|}{$\alpha_{5}^{1}$} & \multicolumn{4}{|c|}{$\alpha_{5}^{2}$} & \multicolumn{4}{|c|}{$\alpha_{4}$} & \multicolumn{4}{|c|}{$\alpha_{7}$} \\
\hline & RTP1 & 2 & RTP3 & $3-1$ & RTP1 & 2 & RTP3 & $3-1$ & RTP1 & 2 & RTP3 & $3-1$ & RTP1 & 2 & RTP3 & $3-1$ & RTP1 & 2 & RTP3 & $3-1$ \\
\hline \multirow{2}{*}{$\begin{array}{l}\text { Low } \\
\left|\beta^{U N C}\right|\end{array}$} & 1.22 & 0.43 & 0.33 & -0.89 & 1.16 & -0.95 & -0.46 & -1.62 & 1.17 & -0.84 & -0.50 & -1.67 & 1.13 & -0.61 & -0.58 & -1.71 & 1.18 & -0.94 & -0.44 & -1.62 \\
\hline & $(1.60)$ & $(0.34)$ & $(0.32)$ & $(-0.68)$ & $(2.07)$ & $(-1.86)$ & $(-0.91)$ & $(-2.14)$ & $(2.05)$ & $(-1.67)$ & $(-1.01)$ & $(-2.21)$ & $(2.18)$ & $(-1.16)$ & $(-1.33)$ & $(-2.53)$ & $(2.04)$ & $(-1.92)$ & $(-0.90)$ & $(-2.14)$ \\
\hline \multirow[t]{2}{*}{2} & 0.54 & 1.83 & 0.36 & -0.18 & 0.18 & 0.24 & -0.97 & -1.15 & 0.11 & 0.36 & -1.04 & -1.15 & -0.02 & 0.91 & -0.81 & -0.78 & 0.14 & 0.30 & -1.01 & -1.15 \\
\hline & $(0.52)$ & $(1.43)$ & $(0.31)$ & $(-0.12)$ & $(0.31)$ & $(0.35)$ & $(-2.28)$ & $(-1.6)$ & $(0.17)$ & $(0.50)$ & $(-2.45)$ & $(-1.50)$ & $(-0.04)$ & $(1.34)$ & $(-1.85)$ & $(-1.01)$ & $(0.22)$ & $(0.41)$ & $(-2.38)$ & $(-1.49)$ \\
\hline \multirow[t]{2}{*}{3} & 0.56 & 1.71 & 1.04 & 0.48 & 0.02 & 0.15 & -0.33 & -0.35 & 0.02 & 0.24 & -0.22 & -0.24 & 0.12 & 0.66 & 0.15 & 0.02 & 0.01 & 0.13 & -0.24 & -0.25 \\
\hline & $(0.67)$ & $(1.38)$ & $(0.78)$ & $(0.30)$ & $(0.05)$ & $(0.31)$ & $(-0.39)$ & $(-0.37)$ & $(0.05)$ & $(0.50)$ & $(-0.27)$ & $(-0.26)$ & $(0.28)$ & (1.27) & $(0.16)$ & $(0.02)$ & $(0.02)$ & $(0.26)$ & $(-0.27)$ & $(-0.25)$ \\
\hline \multirow[t]{2}{*}{4} & 0.62 & 0.47 & 0.46 & -0.15 & -0.38 & -0.86 & -0.59 & -0.21 & -0.37 & -0.51 & -0.45 & -0.07 & -0.08 & -0.32 & -0.39 & -0.31 & -0.40 & -0.70 & -0.47 & -0.07 \\
\hline & $(0.64)$ & $(0.34)$ & $(0.38)$ & $(-0.10)$ & $(-0.85)$ & $(-1.24)$ & $(-1.21)$ & $(-0.32)$ & $(-0.92)$ & $(-0.68)$ & $(-1.04)$ & $(-0.12)$ & $(-0.19)$ & $(-0.44)$ & $(-0.92)$ & $(-0.51)$ & $(-0.94)$ & $(-0.97)$ & $(-1.06)$ & $(-0.11)$ \\
\hline \multirow[t]{2}{*}{5} & 0.87 & 0.69 & 1.06 & 0.19 & 0.50 & -0.01 & -0.36 & -0.86 & 0.30 & 0.29 & -0.37 & -0.68 & 0.33 & 0.21 & -0.03 & -0.36 & 0.41 & 0.21 & -0.35 & -0.76 \\
\hline & $(0.88)$ & $(0.55)$ & $(0.94)$ & $(0.13)$ & $(1.03)$ & $(-0.02)$ & $(-0.71)$ & $(-1.23)$ & (0.6) & $(0.43)$ & $(-0.74)$ & $(-0.95)$ & $(0.62)$ & $(0.33)$ & $(-0.06)$ & $(-0.47)$ & $(0.83)$ & $(0.33)$ & $(-0.68)$ & $(-1.06)$ \\
\hline \multirow[t]{2}{*}{6} & -0.20 & 1.18 & -0.27 & -0.07 & -0.52 & -0.73 & -1.60 & -1.08 & -0.60 & -0.59 & -1.55 & -0.95 & -0.68 & 0.05 & -1.34 & -0.66 & -0.54 & -0.74 & -1.54 & -1.00 \\
\hline & $(-0.19)$ & $(0.92)$ & $(-0.21)$ & $(-0.04)$ & $(-1.09)$ & $(-1.42)$ & $(-2.8)$ & $(-1.45)$ & $(-1.28)$ & $(-1.08)$ & $(-2.76)$ & $(-1.29)$ & $(-1.64)$ & $(0.08)$ & $(-2.57)$ & $(-1.00)$ & $(-1.12)$ & $(-1.41)$ & $(-2.78)$ & $(-1.36)$ \\
\hline \multirow[t]{2}{*}{7} & 0.11 & -0.49 & 1.05 & 0.94 & -0.72 & -1.70 & -0.54 & 0.18 & -0.70 & -1.67 & -0.53 & 0.18 & -0.52 & -1.56 & 0.01 & 0.53 & -0.66 & -1.74 & -0.50 & 0.16 \\
\hline & $(0.11)$ & $(-0.4)$ & $(0.78)$ & $(0.56)$ & $(-1.19)$ & $(-3.1)$ & $(-0.92)$ & $(0.22)$ & $(-1.06)$ & $(-3.11)$ & $(-0.89)$ & $(0.20)$ & $(-0.91)$ & $(-3.19)$ & $(0.02)$ & $(0.60)$ & $(-1.00)$ & $(-3.28)$ & $(-0.84)$ & $(0.18)$ \\
\hline \multirow[t]{2}{*}{8} & 1.67 & 0.81 & -0.58 & -2.25 & 0.26 & -0.67 & -1.47 & -1.74 & 0.21 & -0.60 & -1.38 & -1.60 & 0.72 & -0.25 & -1.46 & -2.19 & 0.22 & -0.61 & -1.39 & -1.61 \\
\hline & $(1.27)$ & $(0.56)$ & $(-0.49)$ & $(-1.26)$ & $(0.39)$ & $(-1.01)$ & $(-2.85)$ & $(-2.02)$ & $(0.3)$ & $(-0.88)$ & $(-2.64)$ & $(-1.80)$ & $(1.12)$ & $(-0.39)$ & $(-2.97)$ & $(-2.69)$ & $(0.3)$ & $(-0.9)$ & $(-2.59)$ & $(-1.78)$ \\
\hline \multirow[t]{2}{*}{9} & 0.92 & 1.64 & -1.69 & -2.61 & -0.66 & 1.04 & -3.03 & -2.37 & -0.81 & 1.13 & -3.05 & -2.24 & -0.10 & 1.00 & -2.88 & -2.79 & -0.77 & 1.10 & -3.09 & -2.31 \\
\hline & $(0.68)$ & $(1.50)$ & $(-1.35)$ & $(-1.42)$ & $(-0.87)$ & (1.5) & $(-5.05)$ & $(-2.44)$ & $(-1.15)$ & $(1.51)$ & $(-5.09)$ & $(-2.43)$ & $(-0.13)$ & (1.49) & $(-4.73)$ & $(-2.87)$ & $(-1.09)$ & (1.49) & $(-5.03)$ & $(-2.46)$ \\
\hline \multirow{2}{*}{$\begin{array}{l}\text { High } \\
\left|\beta^{U N C}\right|\end{array}$} & 1.61 & 0.16 & -2.40 & -4.02 & 1.37 & -0.77 & -3.20 & -4.57 & 1.69 & -0.52 & -3.15 & -4.84 & 0.95 & -0.57 & -3.16 & -4.11 & 1.55 & -0.65 & -3.08 & -4.64 \\
\hline & $(0.83)$ & $(0.12)$ & $(-1.95)$ & $(-1.75)$ & $(0.64)$ & $(-0.82)$ & $(-5.7)$ & $(-2.05)$ & $(0.70)$ & $(-0.49)$ & $(-6.04)$ & $(-1.96)$ & $(0.47)$ & $(-0.63)$ & $(-6.39)$ & $(-2.00)$ & $(0.65)$ & $(-0.64)$ & $(-6.20)$ & $(-1.89)$ \\
\hline \multirow{2}{*}{$\begin{array}{l}\text { High - } \\
\text { Low }\end{array}$} & 0.39 & -0.26 & -2.74 & & 0.22 & 0.17 & -2.73 & & 0.52 & 0.33 & -2.65 & & -0.18 & 0.03 & -2.58 & & 0.38 & 0.29 & -2.64 & \\
\hline & $(0.19)$ & $(-0.14)$ & $(-1.69)$ & & $(0.10)$ & $(0.16)$ & $(-3.61)$ & & $(0.21)$ & $(0.28)$ & $(-3.7)$ & & $(-0.09)$ & $(0.03)$ & $(-3.92)$ & & $(0.15)$ & $(0.25)$ & $(-3.79)$ & \\
\hline
\end{tabular}




\section{Table 10. Double-sorted portfolios in low-sentiment periods}

This table presents the returns on two-way independently sorted portfolios in low-sentiment periods. Based on the residuals of Eq. (4), we define a low-sentiment month as one in which the residual of the previous month is negative. For each stock in each month, the RTP is computed by the total retail trading volume (sum of buy- and sell-initiated trades by retail investors) divided by the total trading volume, following Brandt et al. (2009). We sort sample stocks by the RTP into three groups and independently sort stocks by $\left|\beta^{U N C}\right|$ into 10 groups. The value-weighted returns on each portfolio and the long-short portfolios- - high RTP - low RTP portfolio (denoted 3-1) and high $\left|\beta^{U N C}\right|-$ low $\left|\beta^{U N C}\right|$ portfolio (denoted High-Low) - are computed and the average excess returns (RET-RF) and risk-adjusted returns $\left(\alpha_{5}^{1}, \alpha_{5}^{2}, \alpha_{4}\right.$, and $\left.\alpha_{7}\right)$ are reported. Newey-West adjusted $t$-statistics are in parentheses. The total sample period is from January 2006 to November 2014.

\begin{tabular}{|c|c|c|c|c|c|c|c|c|c|c|c|c|c|c|c|c|c|c|c|c|}
\hline \multirow[b]{2}{*}{ Decile } & \multicolumn{4}{|c|}{ RET-RF } & \multicolumn{4}{|c|}{$\alpha_{5}^{1}$} & \multicolumn{4}{|c|}{$\alpha_{5}^{2}$} & \multicolumn{4}{|c|}{$\alpha_{4}$} & \multicolumn{4}{|c|}{$\alpha_{7}$} \\
\hline & RTP1 & 2 & RTP3 & $3-1$ & RTP1 & 2 & RTP3 & $3-1$ & RTP1 & 2 & RTP3 & $3-1$ & RTP1 & 2 & RTP3 & $3-1$ & RTP1 & 2 & RTP3 & $3-1$ \\
\hline \multirow{2}{*}{$\begin{array}{l}\text { Low } \\
\left|\beta^{U N C}\right|\end{array}$} & 0.04 & 0.20 & -0.52 & -0.56 & 0.21 & 0.01 & -0.02 & -0.23 & 0.18 & -0.05 & 0.18 & 0.00 & -0.01 & 0.23 & 0.41 & 0.43 & 0.19 & -0.06 & 0.27 & 0.08 \\
\hline & $(0.05)$ & $(0.22)$ & $(-0.56)$ & $(-0.48)$ & $(0.53)$ & $(0.03)$ & $(-0.03)$ & $(-0.3)$ & $(0.43)$ & $(-0.10)$ & $(0.28)$ & $(0.00)$ & $(-0.03)$ & $(0.55)$ & $(0.63)$ & $(0.56)$ & $(0.42)$ & $(-0.12)$ & $(0.38)$ & $(0.10)$ \\
\hline \multirow[t]{2}{*}{2} & 0.34 & 0.05 & -0.95 & -1.29 & 0.58 & -0.05 & -0.26 & -0.84 & 0.69 & 0.48 & 0.08 & -0.61 & 0.32 & 0.66 & -0.08 & -0.40 & 0.64 & 0.44 & 0.10 & -0.55 \\
\hline & $(0.58)$ & $(0.05)$ & $(-1.10)$ & $(-1.24)$ & $(1.32)$ & $(-0.09)$ & $(-0.42)$ & $(-1.10)$ & $(1.54)$ & $(0.8)$ & $(0.13)$ & $(-0.82)$ & $(0.74)$ & $(1.17)$ & $(-0.14)$ & $(-0.57)$ & $(1.52)$ & $(0.76)$ & $(0.15)$ & $(-0.71)$ \\
\hline \multirow[t]{2}{*}{3} & 0.41 & -0.68 & -0.90 & -1.32 & 0.45 & -0.34 & -0.90 & -1.34 & 0.23 & -0.30 & -0.80 & -1.03 & 0.12 & -0.21 & -0.52 & -0.64 & 0.33 & -0.28 & -0.85 & -1.18 \\
\hline & $(0.51)$ & $(-0.76)$ & $(-1.23)$ & $(-1.21)$ & $(1.07)$ & $(-0.66)$ & $(-2.11)$ & $(-2.26)$ & $(0.49)$ & $(-0.56)$ & $(-1.69)$ & $(-1.54)$ & $(0.28)$ & $(-0.42)$ & $(-1.20)$ & $(-1.06)$ & $(0.75)$ & $(-0.53)$ & $(-1.76)$ & $(-1.81)$ \\
\hline \multirow[t]{2}{*}{4} & 0.11 & 0.55 & -0.73 & -0.85 & 0.04 & 0.27 & -0.09 & -0.13 & 0.09 & 0.28 & 0.34 & 0.25 & 0.17 & 0.89 & 0.33 & 0.16 & 0.11 & 0.35 & 0.41 & 0.30 \\
\hline & $(0.15)$ & $(0.61)$ & $(-0.77)$ & $(-0.69)$ & $(0.07)$ & $(0.48)$ & $(-0.15)$ & $(-0.16)$ & $(0.16)$ & $(0.5)$ & $(0.61)$ & $(0.32)$ & $(0.37)$ & $(1.81)$ & $(0.7)$ & $(0.25)$ & $(0.19)$ & $(0.59)$ & $(0.72)$ & $(0.37)$ \\
\hline \multirow[t]{2}{*}{5} & 0.10 & 0.50 & -0.62 & -0.73 & -0.22 & 0.66 & -0.34 & -0.12 & -0.19 & 0.59 & -0.56 & -0.37 & 0.01 & 1.05 & -0.19 & -0.20 & -0.23 & 0.78 & -0.55 & -0.32 \\
\hline & $(0.13)$ & $(0.48)$ & $(-0.68)$ & $(-0.60)$ & $(-0.56)$ & $(1.07)$ & $(-0.59)$ & $(-0.17)$ & $(-0.47)$ & $(0.87)$ & $(-0.9)$ & $(-0.51)$ & $(0.04)$ & (1.66) & $(-0.39)$ & $(-0.34)$ & $(-0.57)$ & (1.18) & $(-0.86)$ & $(-0.42)$ \\
\hline \multirow[t]{2}{*}{6} & -0.17 & 0.02 & -0.63 & -0.46 & -0.85 & -0.59 & -0.31 & 0.53 & -0.58 & -0.28 & -0.09 & 0.49 & 0.19 & 0.63 & 0.16 & -0.03 & -0.66 & -0.31 & -0.10 & 0.56 \\
\hline & $(-0.18)$ & $(0.01)$ & $(-0.73)$ & $(-0.36)$ & $(-1.91)$ & $(-1.24)$ & $(-0.68)$ & $(0.83)$ & $(-1.23)$ & $(-0.50)$ & $(-0.19)$ & $(0.72)$ & $(0.39)$ & $(0.85)$ & $(0.31)$ & $(-0.04)$ & $(-1.44)$ & $(-0.57)$ & $(-0.21)$ & $(0.82)$ \\
\hline \multirow[t]{2}{*}{7} & 0.85 & 0.57 & -1.35 & -2.20 & 0.60 & 0.48 & -0.90 & -1.50 & 0.80 & 0.82 & -0.56 & -1.37 & 1.00 & 1.12 & -0.38 & -1.37 & 0.84 & 0.87 & -0.58 & -1.42 \\
\hline & $(0.85)$ & $(0.53)$ & $(-1.39)$ & $(-1.57)$ & $(1.07)$ & $(0.54)$ & $(-1.37)$ & $(-1.73)$ & $(1.51)$ & $(0.76)$ & $(-0.88)$ & $(-1.64)$ & $(1.92)$ & $(1.28)$ & $(-0.61)$ & $(-1.70)$ & $(1.59)$ & $(0.81)$ & $(-0.89)$ & $(-1.69)$ \\
\hline \multirow[t]{2}{*}{8} & 0.59 & -0.38 & -1.63 & -2.22 & -0.06 & -0.05 & -0.96 & -0.90 & 0.27 & -0.15 & -0.92 & -1.19 & 0.63 & 0.04 & -0.80 & -1.43 & 0.13 & -0.06 & -0.89 & -1.02 \\
\hline & $(0.54)$ & $(-0.38)$ & $(-1.78)$ & $(-1.56)$ & $(-0.09)$ & $(-0.07)$ & $(-1.91)$ & $(-1.08)$ & $(0.35)$ & $(-0.21)$ & $(-1.97)$ & $(-1.34)$ & $(0.92)$ & $(0.07)$ & $(-1.67)$ & $(-1.71)$ & $(0.18)$ & $(-0.09)$ & $(-1.8)$ & $(-1.18)$ \\
\hline \multirow[t]{2}{*}{9} & -0.31 & 0.32 & -0.93 & -0.62 & -0.40 & 0.02 & -0.02 & 0.38 & 0.41 & 0.41 & -0.05 & -0.46 & 0.18 & 0.93 & 0.05 & -0.13 & 0.23 & 0.46 & 0.01 & -0.22 \\
\hline & $(-0.25)$ & $(0.28)$ & $(-0.82)$ & $(-0.37)$ & $(-0.51)$ & $(0.02)$ & $(-0.03)$ & $(0.35)$ & $(0.46)$ & $(0.53)$ & $(-0.07)$ & $(-0.4)$ & $(0.23)$ & (1.12) & $(0.07)$ & $(-0.12)$ & $(0.28)$ & $(0.62)$ & $(0.01)$ & $(-0.20)$ \\
\hline \multirow{2}{*}{$\begin{array}{l}\text { High } \\
\left|\beta^{U N C}\right|\end{array}$} & -0.20 & -0.39 & -1.59 & -1.39 & -0.31 & 0.08 & -1.19 & -0.88 & -1.06 & 0.43 & -0.89 & 0.17 & -0.80 & 0.53 & -0.54 & 0.26 & -1.00 & 0.29 & -0.98 & 0.03 \\
\hline & $(-0.14)$ & $(-0.36)$ & $(-1.56)$ & $(-0.78)$ & $(-0.20)$ & $(0.11)$ & $(-2.48)$ & $(-0.55)$ & $(-0.69)$ & $(0.57)$ & $(-1.63)$ & $(0.10)$ & $(-0.64)$ & $(0.74)$ & $(-1.10)$ & $(0.20)$ & $(-0.65)$ & $(0.38)$ & $(-1.84)$ & $(0.02)$ \\
\hline \multirow{2}{*}{$\begin{array}{l}\text { High - } \\
\text { Low }\end{array}$} & -0.24 & -0.59 & -1.06 & & -0.52 & 0.07 & -1.17 & & -1.24 & 0.48 & -1.07 & & -0.79 & 0.29 & -0.95 & & -1.19 & 0.36 & -1.25 & \\
\hline & $(-0.15)$ & $(-0.42)$ & $(-0.77)$ & & $(-0.33)$ & $(0.08)$ & $(-1.43)$ & & $(-0.78)$ & $(0.52)$ & $(-1.24)$ & & $(-0.6)$ & $(0.35)$ & $(-1.16)$ & & $(-0.74)$ & $(0.38)$ & $(-1.41)$ & \\
\hline
\end{tabular}




\section{Table 11. Fama-MacBeth cross-sectional regressions in high- and low-sentiment periods}

This table shows the time-series averages of the slope coefficients in high-sentiment (Panel A) and lowsentiment (Panel B) periods obtained from regressing monthly excess returns on the absolute uncertainty beta $\left(\left|\beta^{U N C}\right|\right)$, the interaction between the absolute uncertainty beta and a dummy for high levels of retail trading $\left(\left|\beta^{U N C}\right| \times H\right)$, and a set of predictive variables using the Fama-MacBeth methodology. Based on the residuals of Eq. (4), we define a high-sentiment month as one in which the residual of the previous month is positive. Newey-West adjusted $t$-statistics are in parentheses. The sample period is from January 2006 to November 2014.

\begin{tabular}{|c|c|c|c|c|c|}
\hline \multicolumn{6}{|c|}{ Panel A: High-sentiment periods } \\
\hline Variable & $(1)$ & $(2)$ & $(3)$ & $(4)$ & $(5)$ \\
\hline \multirow[t]{2}{*}{$\left|\beta^{U N C}\right| \times H$} & -0.02 & -0.021 & -0.041 & -0.040 & -0.026 \\
\hline & $(-2.22)$ & $(-2.19)$ & $(-3.13)$ & $(-3.10)$ & $(-2.44)$ \\
\hline \multirow[t]{2}{*}{$\left|\beta^{U N C}\right|$} & -0.013 & -0.011 & -0.002 & -0.000 & 0.000 \\
\hline & $(-1.50)$ & $(-1.36)$ & $(-0.21)$ & $(-0.06)$ & $(0.01)$ \\
\hline \multirow[t]{2}{*}{$\beta^{M K T}$} & & -0.006 & -0.005 & -0.004 & -0.001 \\
\hline & & $(-1.58)$ & $(-1.24)$ & $(-0.95)$ & $(-0.28)$ \\
\hline \multirow[t]{2}{*}{ SIZE } & & & -0.004 & -0.004 & -0.005 \\
\hline & & & $(-4.04)$ & $(-3.71)$ & $(-4.30)$ \\
\hline \multirow[t]{2}{*}{$\mathrm{BM}$} & & & 0.008 & 0.008 & 0.006 \\
\hline & & & $(3.88)$ & $(3.79)$ & $(2.48)$ \\
\hline \multirow[t]{2}{*}{ MOM } & & & -0.001 & -0.001 & 0.001 \\
\hline & & & $(-0.32)$ & $(-0.28)$ & $(0.15)$ \\
\hline \multirow[t]{2}{*}{ REV } & & & & 0.005 & 0.009 \\
\hline & & & & $(0.47)$ & $(0.84)$ \\
\hline \multirow[t]{2}{*}{ ILLIQ } & & & & 0.712 & 0.635 \\
\hline & & & & (1.97) & $(1.77)$ \\
\hline \multirow[t]{2}{*}{ COSKEW } & & & & 0.001 & 0.000 \\
\hline & & & & $(0.36)$ & $(0.03)$ \\
\hline \multirow[t]{2}{*}{$\mathrm{I} / \mathrm{A}$} & & & & -0.003 & -0.003 \\
\hline & & & & $(-2.63)$ & $(-2.77)$ \\
\hline \multirow[t]{2}{*}{ ROE } & & & & 0.001 & -0.001 \\
\hline & & & & $(0.67)$ & $(-0.62)$ \\
\hline \multirow[t]{2}{*}{ MAX } & & & & & -0.453 \\
\hline & & & & & $(-5.11)$ \\
\hline
\end{tabular}

Panel B: Low-sentiment periods

\begin{tabular}{cccccc}
\hline Variable & $(1)$ & $(2)$ & $(3)$ & $(4)$ & $(5)$ \\
\hline$\left|\beta^{U N C}\right| \times H$ & -0.009 & -0.009 & -0.010 & -0.009 & -0.003
\end{tabular}




\begin{tabular}{|c|c|c|c|c|c|}
\hline & $(-1.19)$ & $(-1.18)$ & $(-1.90)$ & $(-1.76)$ & $(-0.54)$ \\
\hline \multirow[t]{2}{*}{$\left|\beta^{U N C}\right|$} & 0.001 & 0.001 & 0.001 & 0.001 & 0.001 \\
\hline & $(0.24)$ & $(0.24)$ & $(0.22)$ & $(0.23)$ & $(0.10)$ \\
\hline \multirow[t]{2}{*}{$\beta^{M K T}$} & & -0.003 & -0.002 & -0.002 & -0.002 \\
\hline & & $(-0.95)$ & $(-0.87)$ & $(-0.73)$ & $(-0.70)$ \\
\hline \multirow[t]{2}{*}{ SIZE } & & & -0.001 & -0.001 & -0.001 \\
\hline & & & $(-0.56)$ & $(-0.50)$ & $(-0.91)$ \\
\hline \multirow[t]{2}{*}{$\mathrm{BM}$} & & & 0.005 & 0.005 & 0.004 \\
\hline & & & (1.88) & $(2.11)$ & $(1.55)$ \\
\hline \multirow[t]{2}{*}{ MOM } & & & 0.002 & 0.001 & 0.003 \\
\hline & & & $(0.78)$ & $(0.56)$ & $(1.27)$ \\
\hline \multirow[t]{2}{*}{ REV } & & & & -0.016 & -0.012 \\
\hline & & & & $(-1.91)$ & $(-1.29)$ \\
\hline \multirow[t]{2}{*}{ ILLIQ } & & & & -0.066 & -0.064 \\
\hline & & & & $(-0.44)$ & $(-0.46)$ \\
\hline \multirow[t]{2}{*}{ COSKEW } & & & & 0.001 & -0.001 \\
\hline & & & & $(0.12)$ & $(-0.12)$ \\
\hline \multirow[t]{2}{*}{$\mathrm{I} / \mathrm{A}$} & & & & -0.002 & -0.002 \\
\hline & & & & $(-1.31)$ & $(-1.23)$ \\
\hline \multirow[t]{2}{*}{ ROE } & & & & 0.003 & 0.003 \\
\hline & & & & $(2.31)$ & $(1.86)$ \\
\hline \multirow[t]{2}{*}{ MAX } & & & & & -0.280 \\
\hline & & & & & $(-4.89)$ \\
\hline
\end{tabular}




\section{Table 12. Long-term Fama-MacBeth cross-sectional regressions with retail trading in high- and low-sentiment periods}

This table shows the time-series averages of the slope coefficients in high-sentiment (Panel A) and low-sentiment (Panel B) periods obtained from regressing monthly excess returns two to 12 months ahead against the absolute uncertainty beta $\left(\left|\beta^{U N C}\right|\right)$, the interaction between the absolute uncertainty beta and a dummy for high levels of retail trading $\left(\left|\beta^{U N C}\right| \times H\right)$, and a set of predictive variables using the Fama-MacBeth methodology. Based on the residuals of Eq. (4), we define a high-sentiment month as one in which the residual of the previous month is positive. Newey-West adjusted $t$-statistics are in parentheses. The sample period is from January 1992 to June 2017.

\begin{tabular}{|c|c|c|c|c|c|c|c|c|c|c|c|}
\hline \multicolumn{12}{|c|}{ Panel A: High-sentiment periods } \\
\hline Variable & $n=2$ & $n=3$ & $n=4$ & $n=5$ & $n=6$ & $n=7$ & $n=8$ & $n=9$ & $n=10$ & $n=11$ & $n=12$ \\
\hline \multirow[t]{2}{*}{$\left|\beta^{U N C}\right| \times H$} & -0.026 & -0.026 & -0.027 & -0.025 & -0.025 & -0.025 & -0.024 & -0.024 & -0.025 & -0.024 & -0.024 \\
\hline & $(-2.44)$ & $(-2.46)$ & $(-2.51)$ & $(-2.17)$ & $(-2.13)$ & $(-2.16)$ & $(-2.16)$ & $(-2.19)$ & $(-2.28)$ & $(-2.16)$ & $(-2.22)$ \\
\hline \multirow[t]{2}{*}{$\left|\beta^{U N C}\right|$} & 0.000 & 0.000 & 0.001 & 0.000 & 0.000 & 0.001 & 0.001 & 0.001 & 0.002 & 0.001 & 0.001 \\
\hline & $(0.00)$ & $(0.02)$ & $(0.10)$ & $(0.02)$ & $(0.01)$ & $(0.06)$ & $(0.12)$ & $(0.19)$ & $(0.22)$ & $(0.19)$ & $(0.18)$ \\
\hline \multirow[t]{2}{*}{$\beta^{M K T}$} & -0.001 & -0.001 & -0.001 & -0.001 & -0.002 & -0.001 & -0.001 & -0.001 & -0.002 & -0.002 & -0.001 \\
\hline & $(-0.26)$ & $(-0.20)$ & $(-0.20)$ & $(-0.25)$ & $(-0.34)$ & $(-0.30)$ & $(-0.28)$ & $(-0.3)$ & $(-0.35)$ & $(-0.35)$ & $(-0.32)$ \\
\hline \multirow[t]{2}{*}{ SIZE } & -0.005 & -0.005 & -0.005 & -0.005 & -0.005 & -0.005 & -0.005 & -0.005 & -0.005 & -0.005 & -0.005 \\
\hline & $(-4.35)$ & $(-4.38)$ & $(-4.40)$ & $(-4.37)$ & $(-4.36)$ & $(-4.35)$ & $(-4.33)$ & $(-4.35)$ & $(-4.40)$ & $(-4.44)$ & $(-4.43)$ \\
\hline \multirow[t]{2}{*}{$\mathrm{BM}$} & 0.006 & 0.006 & 0.006 & 0.006 & 0.006 & 0.006 & 0.006 & 0.006 & 0.006 & 0.005 & 0.005 \\
\hline & $(2.44)$ & $(2.46)$ & $(2.42)$ & $(2.45)$ & $(2.45)$ & $(2.47)$ & $(2.44)$ & $(2.40)$ & $(2.36)$ & $(2.35)$ & $(2.29)$ \\
\hline \multirow[t]{2}{*}{ MOM } & 0.001 & 0.000 & 0.000 & 0.000 & 0.000 & 0.000 & 0.000 & 0.000 & -0.001 & -0.001 & -0.001 \\
\hline & $(0.14)$ & $(0.08)$ & $(0.08)$ & $(0.01)$ & $(0.02)$ & $(-0.01)$ & $(-0.04)$ & $(-0.06)$ & $(-0.10)$ & $(-0.17)$ & $(-0.19)$ \\
\hline \multirow[t]{2}{*}{ REV } & 0.009 & 0.008 & 0.008 & 0.007 & 0.007 & 0.006 & 0.007 & 0.006 & 0.007 & 0.007 & 0.007 \\
\hline & $(0.79)$ & $(0.76)$ & $(0.75)$ & $(0.64)$ & $(0.64)$ & $(0.56)$ & $(0.58)$ & $(0.53)$ & $(0.57)$ & $(0.62)$ & $(0.66)$ \\
\hline \multirow[t]{2}{*}{ ILLIQ } & 0.637 & 0.639 & 0.641 & 0.641 & 0.638 & 0.634 & 0.635 & 0.636 & 0.630 & 0.620 & 0.623 \\
\hline & $(1.77)$ & (1.77) & $(1.77)$ & $(1.77)$ & $(1.76)$ & $(1.76)$ & $(1.76)$ & $(1.76)$ & $(1.75)$ & $(1.74)$ & $(1.75)$ \\
\hline \multirow[t]{2}{*}{ COSKEW } & 0.000 & 0.000 & 0.000 & 0.001 & 0.001 & 0.001 & 0.001 & 0.001 & 0.001 & 0.001 & 0.001 \\
\hline & $(0.02)$ & $(0.06)$ & $(0.03)$ & $(0.14)$ & $(0.26)$ & $(0.27)$ & $(0.23)$ & $(0.26)$ & $(0.19)$ & $(0.16)$ & $(0.14)$ \\
\hline $\mathrm{I} / \mathrm{A}$ & -0.003 & -0.003 & -0.003 & -0.003 & -0.003 & -0.002 & -0.002 & -0.002 & -0.002 & -0.002 & -0.002 \\
\hline
\end{tabular}




\begin{tabular}{|c|c|c|c|c|c|c|c|c|c|c|c|}
\hline & $(-2.74)$ & $(-2.81)$ & $(-2.95)$ & $(-2.70)$ & $(-2.39)$ & $(-2.16)$ & $(-2.22)$ & $(-2.24)$ & $(-2.02)$ & $(-2.01)$ & $(-1.98)$ \\
\hline \multirow[t]{2}{*}{ ROE } & -0.001 & -0.001 & -0.001 & -0.001 & -0.001 & -0.001 & -0.001 & -0.001 & -0.001 & -0.001 & -0.001 \\
\hline & $(-0.63)$ & $(-0.67)$ & $(-0.56)$ & $(-0.54)$ & $(-0.65)$ & $(-0.63)$ & $(-0.74)$ & $(-0.83)$ & $(-0.96)$ & $(-1.03)$ & $(-1.05)$ \\
\hline \multirow[t]{2}{*}{ MAX } & -0.451 & -0.447 & -0.444 & -0.442 & -0.440 & -0.438 & -0.435 & -0.437 & -0.433 & -0.424 & -0.423 \\
\hline & $(-5.11)$ & $(-5.02)$ & $(-5.02)$ & $(-5.03)$ & $(-4.94)$ & $(-4.90)$ & $(-4.83)$ & $(-4.85)$ & $(-4.79)$ & $(-4.73)$ & $(-4.70)$ \\
\hline \multicolumn{12}{|c|}{ Panel B: Low-sentiment periods } \\
\hline Variable & $n=2$ & $n=3$ & $n=4$ & $n=5$ & $n=6$ & $n=7$ & $n=8$ & $n=9$ & $n=10$ & $n=11$ & $n=12$ \\
\hline \multirow[t]{2}{*}{$\left|\beta^{U N C}\right| \times H$} & -0.003 & -0.003 & -0.002 & -0.002 & -0.002 & -0.001 & -0.001 & -0.001 & -0.001 & -0.001 & -0.001 \\
\hline & $(-0.53)$ & $(-0.51)$ & $(-0.44)$ & $(-0.44)$ & $(-0.47)$ & $(-0.19)$ & $(-0.16)$ & $(-0.15)$ & $(-0.16)$ & $(-0.24)$ & $(-0.26)$ \\
\hline \multirow[t]{2}{*}{$\left|\beta^{U N C}\right|$} & 0.001 & 0.001 & 0.000 & 0.000 & 0.000 & 0.001 & 0.001 & 0.001 & 0.001 & 0.001 & 0.001 \\
\hline & $(0.09)$ & $(0.08)$ & $(0.04)$ & $(0.07)$ & $(0.05)$ & $(0.10)$ & $(0.10)$ & $(0.17)$ & $(0.17)$ & $(0.21)$ & $(0.22)$ \\
\hline \multirow[t]{2}{*}{$\beta^{M K T}$} & -0.002 & -0.001 & -0.001 & -0.001 & -0.001 & -0.001 & -0.001 & -0.001 & -0.001 & -0.001 & -0.001 \\
\hline & $(-0.69)$ & $(-0.66)$ & $(-0.53)$ & $(-0.48)$ & $(-0.49)$ & $(-0.39)$ & $(-0.36)$ & $(-0.41)$ & $(-0.44)$ & $(-0.45)$ & $(-0.47)$ \\
\hline \multirow[t]{2}{*}{ SIZE } & -0.001 & -0.001 & -0.001 & -0.001 & -0.001 & -0.001 & -0.001 & -0.001 & -0.001 & -0.001 & -0.001 \\
\hline & $(-0.91)$ & $(-0.91)$ & $(-0.91)$ & $(-0.91)$ & $(-0.96)$ & $(-0.98)$ & $(-1.00)$ & $(-1.01)$ & $(-1.01)$ & $(-1.04)$ & $(-1.09)$ \\
\hline \multirow[t]{2}{*}{$\mathrm{BM}$} & 0.004 & 0.004 & 0.004 & 0.004 & 0.004 & 0.004 & 0.004 & 0.004 & 0.003 & 0.003 & 0.003 \\
\hline & $(1.57)$ & $(1.55)$ & $(1.52)$ & $(1.51)$ & $(1.49)$ & $(1.45)$ & (1.39) & $(1.38)$ & $(1.34)$ & $(1.27)$ & $(1.27)$ \\
\hline \multirow[t]{2}{*}{ MOM } & 0.003 & 0.003 & 0.003 & 0.002 & 0.002 & 0.002 & 0.002 & 0.002 & 0.002 & 0.002 & 0.002 \\
\hline & $(1.26)$ & $(1.25)$ & $(1.21)$ & $(1.16)$ & $(1.13)$ & $(1.06)$ & $(1.01)$ & $(0.99)$ & $(0.96)$ & $(0.96)$ & $(0.95)$ \\
\hline \multirow[t]{2}{*}{ REV } & -0.012 & -0.012 & -0.013 & -0.013 & -0.014 & -0.014 & -0.014 & -0.014 & -0.013 & -0.013 & -0.013 \\
\hline & $(-1.3)$ & $(-1.32)$ & $(-1.36)$ & $(-1.43)$ & $(-1.51)$ & $(-1.52)$ & $(-1.51)$ & $(-1.55)$ & $(-1.43)$ & $(-1.38)$ & $(-1.41)$ \\
\hline \multirow[t]{2}{*}{ ILLIQ } & -0.068 & -0.072 & -0.081 & -0.080 & -0.083 & -0.087 & -0.087 & -0.091 & -0.093 & -0.095 & -0.098 \\
\hline & $(-0.49)$ & $(-0.53)$ & $(-0.58)$ & $(-0.57)$ & $(-0.60)$ & $(-0.63)$ & $(-0.63)$ & $(-0.67)$ & $(-0.69)$ & $(-0.69)$ & $(-0.72)$ \\
\hline \multirow[t]{2}{*}{ COSKEW } & -0.001 & -0.001 & -0.001 & -0.001 & -0.001 & -0.001 & -0.001 & -0.001 & -0.001 & -0.001 & -0.001 \\
\hline & $(-0.16)$ & $(-0.21)$ & $(-0.17)$ & $(-0.18)$ & $(-0.14)$ & $(-0.14)$ & $(-0.16)$ & $(-0.16)$ & $(-0.12)$ & $(-0.15)$ & $(-0.13)$ \\
\hline \multirow[t]{2}{*}{$\mathrm{I} / \mathrm{A}$} & -0.002 & -0.002 & -0.002 & -0.002 & -0.002 & -0.002 & -0.002 & -0.002 & -0.002 & -0.002 & -0.002 \\
\hline & $(-1.17)$ & $(-1.14)$ & $(-1.09)$ & $(-1.04)$ & $(-1.14)$ & $(-0.99)$ & $(-1.00)$ & $(-1.04)$ & $(-0.98)$ & $(-0.98)$ & $(-0.98)$ \\
\hline ROE & 0.003 & 0.003 & 0.003 & 0.003 & 0.003 & 0.003 & 0.003 & 0.003 & 0.003 & 0.003 & 0.003 \\
\hline
\end{tabular}




\begin{tabular}{lllllllllllll}
\multirow{3}{*}{ MAX } & $(1.85)$ & $(1.84)$ & $(1.81)$ & $(1.83)$ & $(1.81)$ & $(1.63)$ & $(1.57)$ & $(1.64)$ & $(1.60)$ & $(1.56)$ & $(1.69)$ \\
& -0.278 & -0.278 & -0.277 & -0.270 & -0.263 & -0.260 & -0.256 & -0.248 & -0.243 & -0.242 & -0.241 \\
& $(-4.85)$ & $(-4.82)$ & $(-4.85)$ & $(-4.80)$ & $(-4.76)$ & $(-4.69)$ & $(-4.63)$ & $(-4.40)$ & $(-4.34)$ & $(-4.48)$ & $(-4.52)$ \\
\hline
\end{tabular}

